\title{
New Evidence for Southeast Asian Pleistocene Foraging Economies: Faunal Remains from the Early Levels of Lang Rongrien Rockshelter, Krabi, Thailand
}

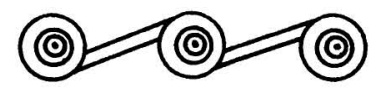

\author{
KAREN MUDAR AND DOUGLAS ANDERSON
}

\section{INTRODUCTION}

RESEARCH OVER THE PAST SEVERAL DECADES has pushed dates for colonization of Australia, New Guinea, and nearby islands into the Pleistocene epoch (Allen 1996; Allen and O'Connell 2003; Balme 1980; Barbetti 1981; Dortch 1979; Groube et al. 1986; Holdaway and Porch 1996; Pearce and Barbetti 1981). The geographic source for human populations that colonized Australia and New Guinea was undoubtedly mainland Southeast Asia. As Figure 1 illustrates, lower sea levels for most of the Pleistocene united the present islands of Sumatra, Java, Borneo, and the Malay Peninsula into a single large land mass called Sundaland that covered almost 2 million $\mathrm{km}^{2}$ (Ollier 1980). The interior of this subcontinent was drained by a large river system that emptied into the China Sea to the northeast.

Several models have been put forward to reconstruct patterns of adaptation and dispersal throughout the new country. One model (Bowdler 1977, 1996) argues that initial migrants focused on exploitation of maritime resources and explored coastal areas before moving inland into new environments. Another model (Rindos and Webb 1992) argues that migrants to new environments did not require specialized skills and that dispersal throughout all areas of the country occurred relatively quickly.

Mulvaney and Kamminga (1999:132) point out that ethnographically known Australian indigenous groups living in proximity to maritime resources also have an inland component to the seasonal round. Groups that fished, hunted marine mammals and turtles, and gathered molluscs in coastal environments also moved inland on a seasonal basis to hunt terrestrial animals and gather plants. A seasonal round that facilitated the exploration of new environments while maintaining a

Karen Mudar is an archeologist with the Archeology Program, National Park Service, Washington, DC. Douglas Anderson is a professor in the Department of Anthropology, Brown University, Providence, Rhode Island. 
stable foraging base would have provided adaptational advantages in unknown environments. Is there evidence that this type of foraging strategy was practiced in Southeast Asia?

At present, there are few sites in Southeast Asia that can shed light on the nature of the foraging strategies required for successful colonization. Known Pleistocene age sites in Sundaland include Leang Burung 2 in Sulawesi (Glover 1981), Niah Cave in Borneo (Harrison 1970; Zuraina 1982), and Tabon Cave on Palawan Island (Fox 1970). At the time of occupation, most were located well inland of the coast and appear to have been utilized as base camps for long-term use.

Recent excavations at Lang Rongrien Rockshelter, on the western side of the Malay Peninsula (see Fig. 1) have revealed evidence for habitation during a period of the Pleistocene epoch that predates the Last Glacial Maximum and is approximately contemporary with colonization of Australia and New Guinea. The composition of the faunal assemblage supports an interpretation of intermittent seasonal use, similar to seasonal rounds observed ethnographically among aboriginal groups in Australia. Lang Rongrien Rockshelter thus may represent one node in a settlement pattern that included regular movement between the marine coast to the west, across a wide coastal plain, to inland stream valleys between low, isolated mountains. The well-preserved faunal remains allow an opportunity to examine a foraging strategy not represented by the assemblages from long-term use sites, but one that may have contributed to the successful colonization of Australia and New Guinea.

\section{BACKGROUND}

\section{Summary Site Information}

Lang Rongrien Rockshelter is located at $75 \mathrm{~m}$ amsl in the upper watershed of the Krabi River, Krabi Province, Thailand (Fig. 2). The Krabi River currently drains south into the Andaman Sea on the west side of the Malay Peninsula. This river rises in a low valley between Khao Ao Pong $(644 \mathrm{~m}$ amsl) to the west and Khao Phanom Bencha (1362 $\mathrm{m}$ amsl) to the east. The mountains are isolated; east of Khao Phanom Bencha is a relatively flat plain that stretches for approximately $90 \mathrm{~km}$ to low mountains to the east and almost $200 \mathrm{~km}$ to low mountains to the southeast. The closest comparable elevations to Khao Phanom Bencha occur almost $120 \mathrm{~km}$ to the northwest, north of the present-day island of Phuket.

Lang Rongrien Rockshelter is $4 \mathrm{~km}$ upstream from the confluence of the Krabi River and its major tributary, the Klong Yai, and is situated in a karstic formation that separates the two stream valleys. The shelter is about $1 \mathrm{~km}$ equidistant between the narrow Krabi River valley and the wider Klong Yai stream valley. This latter valley is approximately $5 \mathrm{~km}$ wide and is drained by three tributaries of the Klong Yai. The rock shelter is located about $35 \mathrm{~m}$ above the floor of the stream valleys.

The opening of the spacious and dry Lang Rongrien Rockshelter faces south and is about $36 \mathrm{~m}$ wide and $18 \mathrm{~m}$ deep. The site was excavated in four seasons between 1974 and 1990 (Anderson 1990, 1997). Excavators encountered a series of stratified cultural levels that dated from 43,000 B.P. to recent times (Anderson 1990). Six cultural layers (Units 1-6) terminated in a sterile layer of limestone debris (Unit 7) composed of rock fall from the roof of the shelter. The two lower 


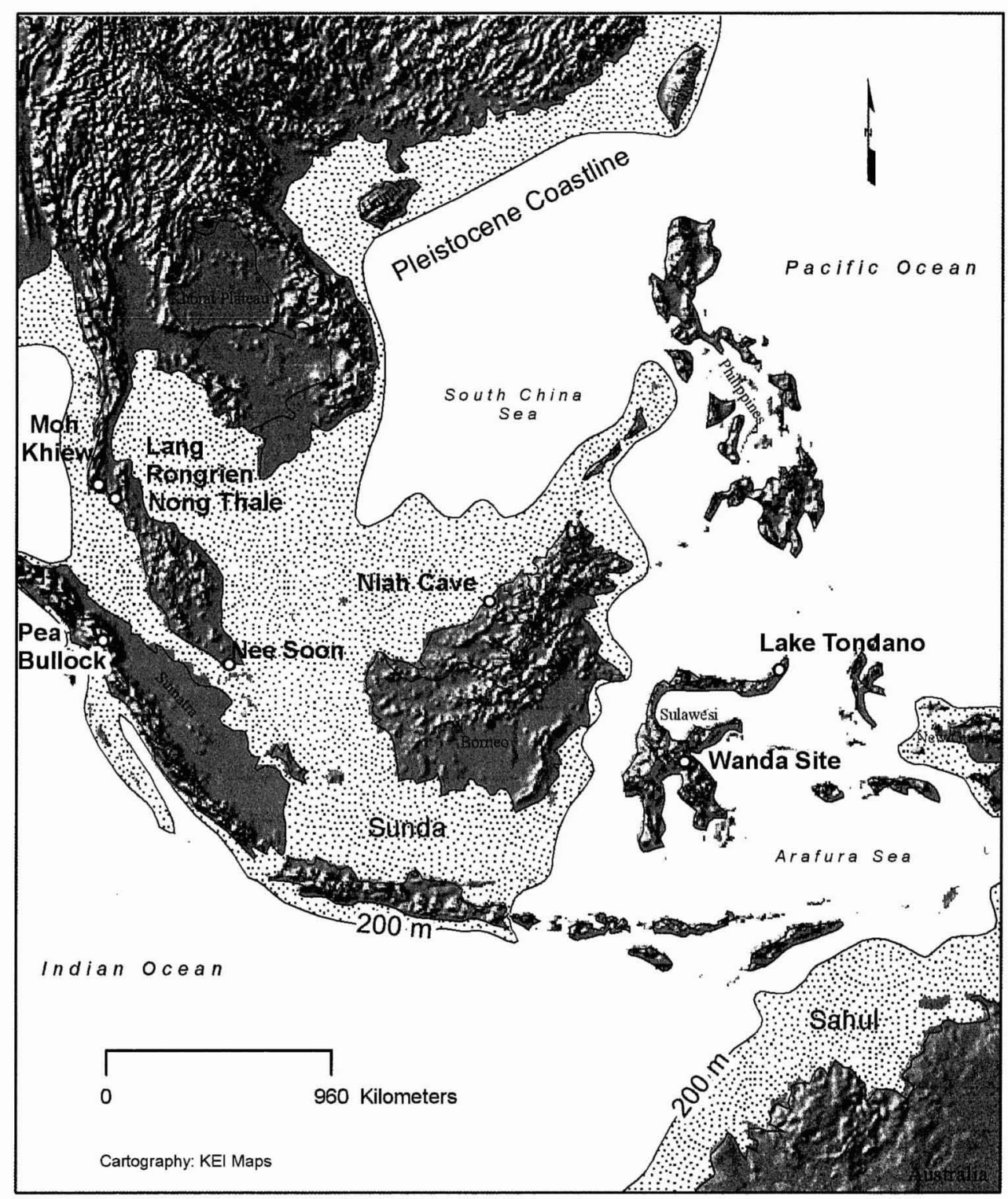

Fig. 1. Sundaland at Late Glacial Maximum.

cultural layers of the upper levels, Units 5 and 6, are dated to 8,300-10,000 B.P., well after the Last Glacial Maximum, and are characterized as Hoabinhian occupations. Lang Rongrien Rockshelter does not appear to have been utilized during the Last Glacial Maximum.

Probing the rock fall revealed evidence of three episodes of cultural activity below the 1-1.5 m thick layer of limestone debris. Cumulatively, these lower deposits were a little over $0.5 \mathrm{~m}$ deep and sloped slightly downward to the north toward the back of the cave (Anderson 1990: Fig. 15). Two weathered paleosols, 


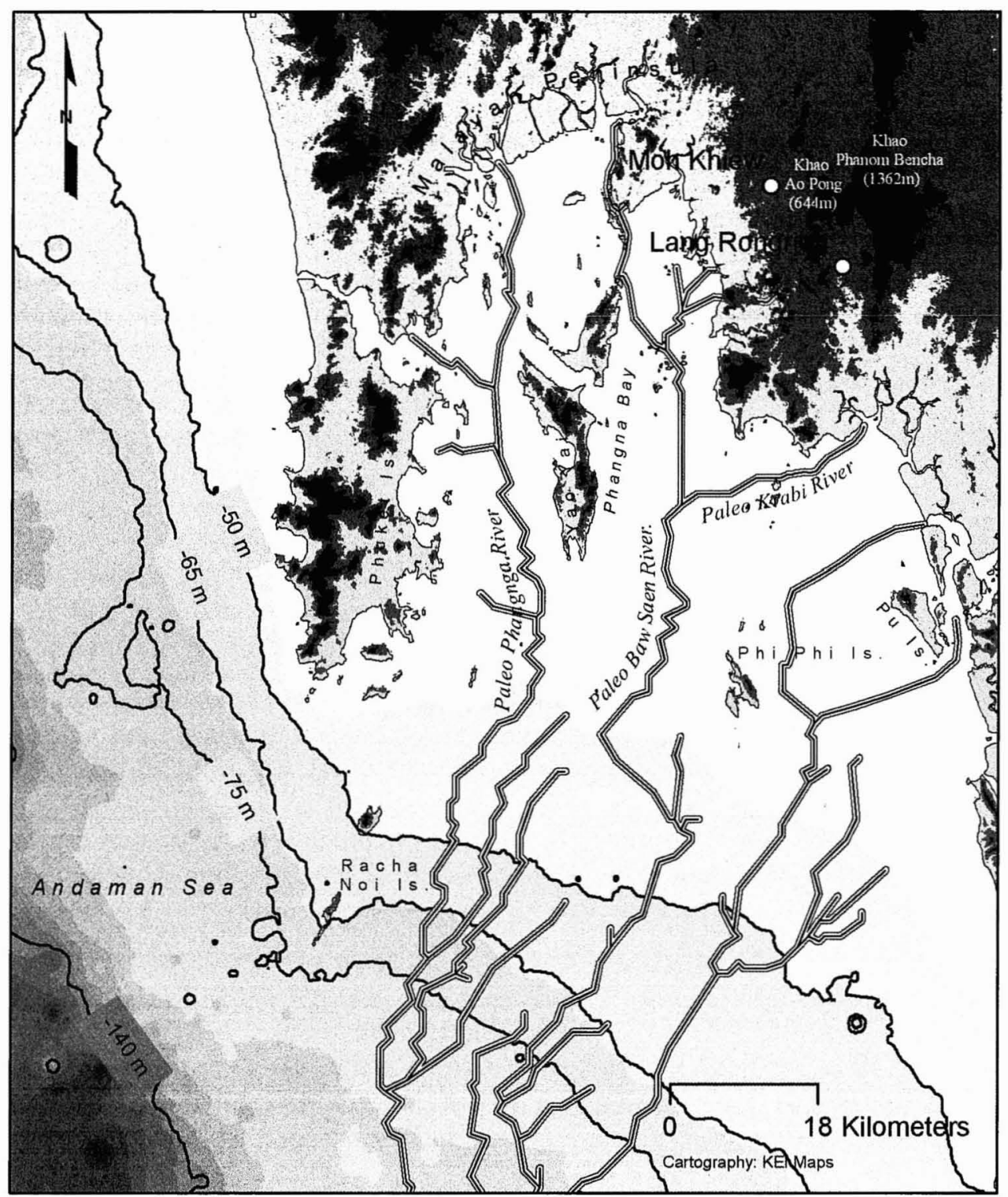

Fig. 2. Reconstruction of riverine palaeo-channels and Pleistocene shorelines in the vicinity of Lang Rongrien Rockshelter (see Appendix for information about preparation of this figure).

Units 8 and 9, each capped by a cultural stratum, were identified. Units 8 and 9 were for the most part only 2 to $3 \mathrm{~cm}$ thick, separated by a distinct thin layer of decomposed limestone. Most of the cultural materials were in the uppermost part of each unit. All of the cultural objects lay flat, suggesting that there had been little or no soil movement over time. The cultural materials were generally associated with hearths and ash deposits. Within each unit, the excavators encountered relatively tight clusters of stone tools and flakes in and around the 
features and the somewhat larger scatters of bones nearby (Figs. 4, 5). None of the features within each unit overlapped, which suggests that the activities represented by the remains took place within a relatively short period of time. Occupation of Unit 8 has been dated to 27,000 B.P.; Unit 9 has been dated to 37,000 B.P. (Anderson 1997).

Unit 10 consisted of a cultural stratum immediately above the rock floor of the shelter and was much thicker than the other two units. The top of Unit 10 was a distinct grayish color, apparently a mixture of charcoal, ash, and limestone that graded downward into sterile decomposed limestone underneath. The cultural remains in this unit, although also lying flat, were more diffusely scattered throughout the deposit, especially in the area of a large ash lens near the rear of the rock shelter (Fig. 3). It appears that the span of time during which the objects were deposited was longer than the span of time for Unit 8 and Unit 9 . Unit 10 has been dated to 43,000 B.P. (Anderson 1997).

Units 8-10 yielded a series of hearths, pits, and stone tools. The 45 stone tools are characterized as a "flake and chopper industry" (Anderson 1990) and are distinctive from the Hoabinhian assemblages that occur in upper levels of Lang Rongrien. The stone tools from Units 8-10 include cores and core tools such as choppers, bifaces, and a hand adze, as well as flake scrapers, retouched and utilized flakes, and a flake knife. There is no evidence that toolmaking activities took place in the cave. All of the artifacts were made from local chert, with the exception of six unutilized flakes that were made from shale.

In addition to stone tools, excavators encountered well-preserved animal bones. Nearly all of the faunal remains from the three superimposed Pleistocene levels were collected in situ. The analysis of a sample of this assemblage of animal bones provides an opportunity to investigate animal exploitation practices in Southeast Asia dating to a time prior to the Last Glacial Maximum and to identify foraging strategies that may have contributed to the successful colonization of Australia and New Guinea.

\section{Pleistocene Sea Levels in Southeast Asia}

Recent research (Chappell et al. 1986; Lamback and Chappell 2001; Tijia, Shoji, and Kunihiko 1977) documenting sea level changes has demonstrated that, beginning about 120,000 years ago, sea level gradually dropped worldwide as water volume increased in ice sheets in the northern hemisphere. Sea level reached the lowest point about 20,000 B.P. during the Last Glacial Maximum, then reversed as global warming caused ice sheets to melt. Present sea level results from this latest warming trend.

The drop in sea level exposed a wide, flat coastal plain on the west side of the upper Malay Peninsula. At present, Lang Rongrien is located about $12 \mathrm{~km}$ upstream from the mouth of the Krabi River and about $14 \mathrm{~km}$ due east of the coast (see Table 1). At 43,000 B.P., the earliest dated occupation, however, sea level was approximately $65 \mathrm{~m}$ below current mean sea level (Lambeck and Chappell 2001), and the rock shelter was located about $85 \mathrm{~km}$ due east of the coast. Sea level continued to drop; at 37,000 B.P., the date of Unit 9 occupations, sea level was $75 \mathrm{~m}$ below current mean sea level. By 27,000 B.P., the age of Unit 8 occupations, sea level was approaching Last Glacial Maximum levels of $140 \mathrm{~m}$ below current mean sea level. Lang Rongrien was then located $110 \mathrm{~km}$ due east of the coast. By 
Table i. Occupational Dates, Sea Levels, and Distance from Nearest Marine Coast at Time of Occupation of Lang Rongrien Rockshelter, Krabi Province, THAILAND.

\begin{tabular}{lccc}
\hline $\begin{array}{l}\text { EXCAVATION } \\
\text { UNit }\end{array}$ & $\begin{array}{c}\text { DATE }^{1} \\
\text { (B.P.) }\end{array}$ & $\begin{array}{c}\text { SEA LEVEL BelOW CURRENT } \\
\text { MEAN SEA LEVEL (M) }\end{array}$ & $\begin{array}{c}\text { DistANCE FROM COAST } \\
\text { (KM) }\end{array}$ \\
\hline Surface & Present & 0 & 14 \\
Unit 6 & 10,000 & 50 & 74 \\
Unit 8 & 27,000 & 140 & 110 \\
Unit 9 & 37,000 & 75 & 90 \\
Unit 10 & 43,000 & 65 & 85 \\
\hline
\end{tabular}

Notes:

1. Radiocarbon dates from Anderson (1997).

2. Sea levels from Lambeck and Chappell (2001).

8,000-10,000 B.P., the dates of Unit 5 and 6 occupations, the post-Last Glacial Maximum sea level was rising rapidly, and Lang Rongrien was $75 \mathrm{~km}$ from the coast.

Currently, Lang Rongrien Rockshelter is located in the upper reaches of the short Krabi River that discharges into lower Phangna Bay. During much of the Pleistocene, however, the Krabi River was probably part of the palaeo-Baw Saen River. At present, the Baw Saen River discharges into Phangna Bay to the west of the Krabi River. The palaeo-Baw Saen River probably meandered south across the broad coastal plain after emerging from the encircling hills that today form Phi Phi and Yao Yai Islands. Based on soundings taken in 1939-1942, we suggest that the palaeo-Krabi River swung west to join the palaeo-Baw Saen north of the Phi Phi islands (see Fig. 2).

At the time of earliest occupation of the site, therefore, Lang Rongrien was situated in a narrow, north-south trending valley formed by a low ridge to the west and a granitic mountain on the east. The elevations were isolated by broad coastal plains and interior flatlands. The site was located in the upper reaches of a $100-$ $200 \mathrm{~km}$ long river that discharged into the Andaman Sea.

\section{Climate and Vegetation in Southeast Asia Prior to Last Glacial Maximum}

At present, southern Thailand is located in a tropical monsoonal climate (Walker $1980: 22)$ that experiences a short dry season dominated by the northeast monsoon and a longer wet season dominated by the southwest monsoon. According to Thailand's Ministry of Communication, the immediate locality of Lang Rongrien Rockshelter receives $238 \mathrm{~cm}$ of rainfall annually. This rainfall regime has allowed the establishment of lowland tropical rainforest dominated by Dipterocarpaceae genera (White et al. 2003:114).

Several recent studies have provided evidence to begin reconstruction of climate and vegetation regimes prior to the Last Glacial Maximum in Southeast Asia. Stable oxygen isotope ratios in calcite layers of stalagmites removed from caves in Socotre Island in the western Indian Ocean suggest that changes in the rainfall regimes that produced the stalagmites are related to varying intensities of tropical convective activity. Fluctuating oxygen isotope ratios reflect changes in tropical hydrological cycles in the Indian Ocean and, possibly, over Southeast 
Asia: "Because rainfall on the island is related to intensity of tropical convective activity, it is likely representative of tropical hydrological cycles in the Indian Ocean and perhaps of variations in monsoon rainfall over a much larger area" (Burns et al. 2003:1366). The study suggests that changes in precipitation regimes and monsoonal intensity occurred in tandem in the western and eastern Indian Ocean. Burns et al. conclude that climate conditions over the Indian Ocean-and, more generally, worldwide-were drier prior to the Last Glacial Maximum. The results from Socotre Island, therefore, suggest that drier conditions than at present prevailed in Southeast Asia during the earliest occupations of Lang Rongrien Rockshelter.

Palaeobotanical studies from other parts of Sundaland provide concurrence that in general, the regional climate was drier prior to the Last Glacial Maximum. Pollen cores from three sites at elevations of $180 \mathrm{~m}$ amsl in northeastern Thailand dating to $40,000-10,000$ B.P. indicate that the dominant species contributing to the cores were Pinus and Quercus (Penny 2001). In contrast to present restricted ranges that exclude this region, Pinus displayed a more widespread distribution during periods of cooler and/or more arid climates (Werner 1997, cited in Penny 2001). The presence of pines in pollen samples from the Khorat Plateau indicates that a cooler and drier climate prevailed in this region of Southeast Asia at 38,300 B.P.

Geomorphological data from Lake Tondano, $68 \mathrm{~m}$ amsl, northern Sulawesi (Dam et al. 2001), suggests that the climate in the region at 30,000 B.P. was characterized by low rainfall, high evaporation rates, and strong seasonality in precipitation.

A palynological study of cores taken from a peat swamp in south Sulawesi dating to 30,000 B.P. (Hope 2001) identified montane forest species currently found above $850 \mathrm{~m}$ amsl at the Wanda site, located at $450 \mathrm{~m}$ amsl. The composition of the palynological core suggested that the climate was cooler and that the forest diversity was reduced, indicating that the climate was more arid than at present.

In contrast to these findings, palynological studies at Pea Bullock, $1400 \mathrm{~m}$ amsl, northern Sumatra, suggest that climatic conditions at 32,000 B.P. were warm and wet, similar to those at present (Maloney and McCormac 1996). Low percentages of fern pollen spores relative to total pollen in the sample, however, suggested to the researchers that a different interpretation is possible and that the climate was drier than at present. At 29,000 B.P., higher montane forest elements were represented in the samples and conditions were drier and cooler than at present.

Accumulating evidence from a number of fields demonstrate that worldwide, dropping sea level during the Pleistocene epoch was associated with lower average temperatures and a more arid and seasonal rainfall regime than at present. Although the currently available Southeast Asian data come from areas that are on the periphery of the former subcontinent, palaeobotanical and geomorphological findings indicate that-leading up to the Last Glacial Maximum and coincident with the earliest occupations of Lang Rongrien-there was decreased rainfall, increased evapotranspiration, and perhaps increased seasonality of rainfall across Sundaland. Evidence for depressed elevational limits of different vegetational types (Maloney and McCormac 1996; Penny 2001; Taylor et al. 2001) suggests that the annual average temperature was lower. Burns et al. (2003) suggest that the surface sea temperature during this time was depressed by up to $2{ }^{\circ} \mathrm{C}$. 
Maloney and McCormac's (1996) findings that climatic conditions in northern Sumatra at 32,000 B.P. were similar to present conditions are difficult to reconcile with other studies illustrating increased aridity and cooling temperatures. The location of the study site on the west side of Sundaland and more exposed to southeast monsoons, even if monsoons were decreased in duration and intensity, may be a factor. The high altitude of the Pea Bullock site in comparison to the other study sites may account for the species composition of pollen cores leading to an interpretation of wetter conditions. Within altitudinal limits, floral changes in response to climate change at high elevations may lag changes at low elevations. High-altitude species may be expanding ranges during climate change; sampling within a high-altitude environment, therefore, may not identify evidence for climate change until the upper limits of the species distribution are depressed.

The impact of decreased rainfall, increased seasonality of rainfall, and lower annual average temperatures on vegetation in the vicinity of Lang Rongrien Rockshelter has not been established. Palynological analysis of a core taken from Nong Thale Song Hong, a lake $100 \mathrm{~m}$ amsl $75 \mathrm{~km}$ south of Lang Rongrien, indicates that open forest dominated by Castanopsis sp. (Fagaceae) was present during the Last Glacial Maximum (White et al. 2003). Kealhofer (2002, 2003), however, argues that the phytolith evidence indicates the presence of a savannah-like environment dominated by grasses. Discontinuities in the pollen sequence in the lower portions of the core from Nong Thale Song Hong are likely caused by evaporation of the lake, signaling a dry climate prior to 17,500 B.P. Geomorphological evidence (de Dapper, cited in Anderson 1990:28) indicates that the vegetational patterns on the west side of Sundaland fluctuated between savannah-like habitat and forest throughout the Pleistocene; correlations with dated climatic fluctuations were not established.

These studies indicate that the earliest inhabitants of Lang Rongrien experienced a drier and more seasonal climate than currently found in the region. Palaeobotanical studies suggest that by the Last Glacial Maximum, the region may have been covered in a mosaic of savannah and forest dominated by members of Fagaceae rather than Dipterocarpaceae. This brief sketch of the climatic and environmental background provides a framework for assessing the characteristics of the faunal assemblage from the Pleistocene deposits of Lang Rongrien Rockshelter.

\section{METHODS}

The animal bones considered in this study come from excavation of Units 8-10 of Lang Rongrien Rockshelter. Faunal remains encountered during excavation of each unit were mapped. Additional bones were recovered through screening; all soil from the excavations was passed through a $0.5 \mathrm{~mm}$ screen (Anderson $1990: 8)$.

The faunal remains discussed here are a subset of the animal bones excavated at Lang Rongrien Rockshelter; the entire assemblage was not available at the time of analysis. The size of this sample to the total assemblage is not available, but it is thought to be a large proportion and is assumed to be representative of the total assemblage, as none of the bone assemblages from units chosen for analysis were presorted. Issues pertaining to ratios and proportions of taxa repre- 
sented, elements present, and assemblage size are provisionally addressed throughout this study.

Although excavation results suggest that the occupational debris in each cultural unit is the result of multiple visits to the rock shelter, the animal bones from each unit are regarded here as a chronologically related series of depositional events for the purposes of this analysis, and they are grouped by cultural level. Bone distribution and burning patterns suggest that most if not all of the bones were transported to the cave by human agents (see below for further discussion).

The faunal remains were sorted into the major taxonomic groups of molluscs, fish, amphibians, reptiles, birds, and mammals. Mammal, bird, and fish bones were identified through comparison with specimens housed in the vertebrate zoology section of the Department of Systematic Biology, National Museum of Natural History, Smithsonian Institution,Washington, DC. A sample of the turtle bones was identified by comparison with the personal skeleton collection of Peter Pritchard. All bones in the sample were weighed and counted.

\section{THE FAUNAL SAMPLE}

A sample from Lang Rongrien containing 2322 animal bones weighing $5135 \mathrm{~g}$ was examined (Table 2). Over half of the assemblage under consideration here1402 bones weighing $2140 \mathrm{~g}$-came from Unit 8 . The sample from Unit 9 consisted of 584 bones weighing $1875 \mathrm{~g}$. A sample of 336 bones weighing $1120 \mathrm{~g}$ was derived from Unit 10 . The species and element compositions of these relatively small faunal samples are no doubt influenced by the vagaries of sample size. Interpretations of species identifications as reflections of resources present in the environment or as preferred hunted species are offered here as propositions that await analysis of larger and more complete faunal assemblage for confirmation. Taxonomic identifications are discussed below.

\section{Molluscs}

Four freshwater or land snail shell fragments and two opercula were noted from Units 8 and 9 . They were not identified to genus or species level.

Table 2. Counts and Weights of Bones in Faunal Sample from Units 8-io, Lang Rongrien Rockshelter, Krabi Province, Thailand (Weights in Grams).

\begin{tabular}{|c|c|c|c|c|c|c|c|c|c|c|c|c|c|c|}
\hline \multirow[b]{2}{*}{ UNIT } & \multicolumn{2}{|c|}{$\begin{array}{l}\text { MOL- } \\
\text { LUSCS }\end{array}$} & \multicolumn{2}{|c|}{ FISH } & \multicolumn{2}{|c|}{$\begin{array}{c}\text { AM- } \\
\text { PHIBIANS }\end{array}$} & \multicolumn{2}{|c|}{ BIRDS } & \multicolumn{2}{|c|}{ REPTILES } & \multicolumn{2}{|c|}{ MAMMALS } & \multicolumn{2}{|c|}{ TOTALS } \\
\hline & NO. & WT. & No. & WT. & NO. & WT. & NO. & WT. & No. & WT. & No. & WT. & No. & WT. \\
\hline 8 & 3 & 4 & 4 & 3 & 2 & 1 & 2 & 2 & 602 & 754 & 789 & 1376 & 1402 & 2140 \\
\hline 9 & 3 & 6 & 4 & 1 & - & - & 1 & 1 & 482 & 1429 & 94 & 438 & 584 & 1875 \\
\hline 10 & - & - & 2 & 1 & - & - & 2 & 1 & 84 & 122 & 248 & 996 & 336 & 1120 \\
\hline Totals & 6 & 10 & 10 & 5 & 2 & 1 & 5 & 4 & 1168 & 2305 & 1131 & 2810 & 2322 & 5135 \\
\hline
\end{tabular}


Fish

Despite Lang Rongrien Rockshelter's proximity to several streams, only seven elements identified as fish were recovered. An articular, two vertebrae, and a scrap of unidentified fish bone were found in Unit 8; it is unknown whether they are from marine or freshwater fish. A series of four "teeth" from the pharyngeal arch or premaxilla of a marine or estuarine fish was found in Unit 9. They resemble the "teeth" found on pharyngeal arches and premaxillas of scarids (Scaridae) or croakers (Scianidae). Unit 10 yielded two fish vertebrae.

\section{Amphibians}

Two bones from Unit 8 were identified as shaft fragments of limb elements of a frog or a toad. Further identification was not possible.

\section{Reptiles}

Almost half of the total sample, both by number (1168) and by weight (2305 g), was composed of bones of freshwater and terrestrial turtles, which were the only reptiles identified at Lang Rongrien Rockshelter. Numbers and weights of all examined turtle and tortoise bones were tabulated by element category: limbs, shell fragments, skull, and vertebrae (Table 3).

Turtles and tortoises are challenging to quantify in meaningful ways, as the plastron and carapace are composed of numerous smaller elements that tend to disarticulate over time. Clusters of disarticulated bones that were recognizable as originally constituting a single carapace or plastron were tabulated as one element. Isolated plastron or carapace fragments were also tabulated as single elements. While the numbers of bones give an indication of density, they are also a reflection of the rate of carapace and plastron fragmentation. Bone weights may give a more accurate picture of turtle and tortoise element distribution but, owing to different preservation conditions, may be difficult to compare between sites.

A total of 602 turtle and tortoise bones weighing $754 \mathrm{~g}$ were identified in the sample from Unit 8, constituting 43 percent of the sample of animal bones from this unit by number and 36 percent by weight. The Unit 9 sample contained 482

Table 3. Counts and Weights of Turtle and Tortoise Bones in Faunal Sample from Units 8-io, Lang Rongrien Rockshelter, Krabi Province, Thailand (Includes Elements That Have Been Identified to Taxon; Weights in Grams).

\begin{tabular}{|c|c|c|c|c|c|c|c|c|c|c|}
\hline \multirow[b]{2}{*}{ UNIT } & \multicolumn{2}{|c|}{ LIMBS } & \multicolumn{2}{|c|}{ CARAPACE \PLASTRON } & \multicolumn{2}{|c|}{ SKULL } & \multicolumn{2}{|c|}{ VERTEBRAE } & \multicolumn{2}{|c|}{ TOTALS } \\
\hline & No.* & wт.* & No. & WT. & No. & WT. & No. & WT. & No. & WT. \\
\hline 8 & (11) 96 & (18) 92 & (132) 490 & 653 & 16 & 9 & - & - & 602 & 754 \\
\hline 9 & 31 & 50 & (38) 443 & (84) 1368 & 2 & 3 & 6 & 8 & 482 & 1429 \\
\hline 10 & 10 & 10 & (3) 71 & (4) 109 & 3 & 3 & - & - & 84 & 122 \\
\hline Totals & 137 & 152 & 1003 & 2129 & 21 & 15 & 6 & 8 & 1168 & 2305 \\
\hline
\end{tabular}

* Counts and weights in parentheses refer to burned bones. 
turtle and tortoise bones weighing $1429 \mathrm{~g}$. Turtle and tortoise comprised 82 percent of the animal bone sample by number and 75 percent of the sample by weight. Turtles and tortoises comprised only 23 percent of the total sample in Unit 10 by number and 10 percent by weight, with 84 bones weighing $122 \mathrm{~g}$ present.

Many of the individual elements of which the plastron and carapace are composed, as well as many of the limb bones, do not display unique species characteristics and are thus difficult to identify. As a comparative collection of skeletal specimens of representative Southeast Asian turtle and tortoise species was not consistently available for this analysis, it was not possible to assess the identification potential for all of the turtle and tortoise remains in the sample from Lang Rongrien. The turtle and tortoise elements discussed in this paper that are identified to the genus/species level are a subsample of all elements identified as turtle and tortoise. The archaeological specimens that made up this subsample were chosen for presence of distinctive features or relative completeness that might aid in species identification; not all of the turtle and tortoise specimens were compared to modern specimens. While it is not possible to provide meaningful relative frequencies or minimum number of individuals (MNIs) for each species, the presence of each identified taxon does provide information about the environments utilized by the Pleistocene inhabitants of Lang Rongrien prior to the Last Glacial Maximum.

\section{Soft-Shelled Turtles (Trionychidae)}

Several carapace fragments from soft-shelled turtles were identified. On the Malay Peninsula, this family is currently represented by four monospecific genera: Dogania, Pelochelys, Amyda, and Chitra. Carapace bones of species in this family display characteristic surface features - either pitting or tubercles - and can be identified by small fragments. Both tubercles and pitting were present on carapace elements in the Lang Rongrien sample, suggesting that at least two species were present.

Four carapace fragments found in Unit 8 are likely to be Dogania based on descriptions of the characteristic surface tubercles. Dogania is a medium-sized turtle, with a maximum carapace length of $30 \mathrm{~cm}$. It prefers "clean hill streams rather than the slow-moving mud bottomed rivers" (Ernst and Barbour 1989:98).

Five pitted carapace bones were found in Unit 8. They are likely to be from Pelochelys, Amyda, or Chitra individuals, all of which exhibited deep pitting on carapace bones. While Amyda is found in a wide variety of habitats, including ponds, swamps, lakes, and upland and lowland streams, Pelochelys is found in streams and deep, slow-moving rivers (Ernst and Barbour 1989:110-111). Chitra "prefers sandy sections of large rivers" (Ernst and Barbour 1989: 112). Judging from the habitat in the vicinity of the cave, the pitted carapacial bones are most likely to be Amyda. All three taxa are large turtles, having maximum carapace lengths of $70-129 \mathrm{~cm}$.

\section{Pond Turtles (Emydidae)}

Most of the turtles identified in the Lang Rongrien sample were emydids, which includes both pond turtles and terrestrial turtles. Several carapace and plastron elements were identified as the Malayan box turtle (Cuora amboinensis) based on 
comparisons with skeletal elements. All Malayan box turtle elements were found in Unit 8. The Malayan box turtle is found in "lowland water bodies with soft bottoms and slow currents, such as marshes, swamps, ponds, pools in streams ... it is often found on land far from water" (Ernst and Barbour 1989:147). This small turtle, up to $20 \mathrm{~cm}$ long, would have been easy to catch on land or in small bodies of water.

A number of shell and limb elements from all three units were identified as the Asian leaf turtle, Cyclemys dentata, based on comparison with skeletal specimens. This species grows up to $20 \mathrm{~cm}$ in length, and is found in shallow streams in both upland and lowland areas of Southeast Asia (Ernst and Barbour 1989:153).

A number of shell and limb elements were identified as the giant Asian pond turtle (Heosemys grandis) based on comparisons with modern specimens. This medium-sized turtle reaches a carapace length of $43 \mathrm{~cm}$ and is found in "rivers, streams, swamps, lakes, and marshes from hill country to sea level. It is not restricted to water" (Ernst and Barbour 1989:158). H. grandis elements were found in Units 8 and 9.

Another medium-sized emydid turtle identified in the sample is the yellowheaded temple turtle (Hieremys annandali). Identifications of elements from all parts of the skeleton were based on comparisons with modern specimens. The yellow-headed temple turtle can grow to a carapace length of $60 \mathrm{~cm}$ and inhabits "swamps, flooded fields, and rivers with slow currents" (Ernst and Barbour $1989: 161)$. Although it was not possible to estimate carapace lengths, several of the bones of this species in the Lang Rongrien sample were very large. H. annandali bones were found in all three cultural units.

A carapace fragment with a posterior buttress from Unit 9 was tentatively identified as the Burmese eyed turtle (Morenia ocellata) based on comparisons with modern skeletons. This small turtle often occurs in "water bodies that seasonally dry up. It probably also lives in permanent rivers, streams, swamps, and ponds" (Ernst and Barbour 1989:175).

\section{Tortoises (Testudinidae)}

A cluster of carapace fragments from Unit 9 was identified as the elongated tortoise (Indotestudo elongata) through comparison with modern specimens. This is a small terrestrial tortoise, reaching a carapace length of $27 \mathrm{~cm}$. It lives in "tropical evergreen and deciduous forests on hills, mountains, and high plateaus" (Ernst and Barbour 1989:244). This species was probably present in the karstic hills around the Klong Yai and Krabi stream valleys.

\section{Lang Rongrien's Turtle Sample and Pleistocene Environmental Reconstruction}

At present, the Malay Peninsula supports approximately 23 species of freshwater and terrestrial turtles and tortoises (Ernst and Barbour 1989) (Table 4). These taxa are found in a variety of habitats, including upland streams, upland terrestrial environments, large rivers and lakes, lowland terrestrial environments, and bodies of water with slow currents and soft bottoms, such as ponds, swamps, flooded fields, and lowland streams. The eight provisionally identified taxa of turtles and tortoises from Lang Rongrien were not a random subset of the possible range of 
Table 4. Nonmarine Turtles and Tortoises Currently Found in Peninsular Southeast Asia.

\begin{tabular}{|c|c|c|c|}
\hline NAME & HABITAT $^{1}$ & $\begin{array}{l}\text { COMPARATIVE } \\
\text { COLLECTION }^{2}\end{array}$ & $\begin{array}{c}\text { LANG } \\
\text { RONGRIEN } \\
\text { SAMPLE }\end{array}$ \\
\hline \multicolumn{4}{|c|}{ Trionychidae } \\
\hline Dogania subplana & Streams: clean hill streams & & ? \\
\hline Amyda cartilaginea & Varied: fast and slow streams, ponds, swamps & & ? \\
\hline Pelochelys bibroni & Streams: streams and rivers & & ? \\
\hline Chitra indica & $\begin{array}{l}\text { Rivers: sandy sections of large rivers; does not } \\
\text { bask }\end{array}$ & & ? \\
\hline \multicolumn{4}{|c|}{$\begin{array}{l}\text { Platysternidae } \\
\end{array}$} \\
\hline $\begin{array}{l}\text { Platysternon } \\
\quad \text { megacephalum }\end{array}$ & Streams: fast, cool, mountain streams & yes & \\
\hline \multicolumn{4}{|c|}{ Emydidae } \\
\hline Batagur baska & $\begin{array}{l}\text { Rivers: estuaries of large rivers, breeds } \\
\text { upstream }\end{array}$ & & \\
\hline Callagur borneoensis & $\begin{array}{l}\text { Rivers: estuaries of large rivers, breeds on sea } \\
\text { beaches }\end{array}$ & & \\
\hline Cuora amboinensis & $\begin{array}{l}\text { Ponds: lowland water bodies with soft } \\
\text { bottoms, slow currents }\end{array}$ & yes & yes \\
\hline Geomyda spengleri & Terrestrial & & \\
\hline Cyclemys dentata & $\begin{array}{l}\text { Streams: shallow streams in lowlands and } \\
\text { mountains }\end{array}$ & yes & yes \\
\hline Heosemys grandis & Varied: rivers, streams, swamps, terrestrial & yes & yes \\
\hline Heosemys spinosa & Streams: shallow, clear mountain streams & yes & \\
\hline Hieremys annandali & $\begin{array}{l}\text { Ponds: swamps, flooded fields, rivers with } \\
\text { slow current }\end{array}$ & yes & yes \\
\hline Malayemys subtrijugata & Ponds: soft bottoms & yes & \\
\hline Morenia ocellata & $\begin{array}{l}\text { Varied: lowland streams, rivers, swamps, } \\
\text { ponds, seasonally drying water }\end{array}$ & & ? \\
\hline Notochelys platynota & Ponds: shallow water bodies with soft bottoms & yes & \\
\hline Orlita borneoensis & Lakes: large water bodies, large rivers & & \\
\hline Pyxidea mouhotti & Terrestrial: mountain-dwelling & yes & \\
\hline Siebenrockella crassicola & $\begin{array}{l}\text { Ponds: slow current, soft bottom, streams, } \\
\text { ponds, lakes }\end{array}$ & yes & \\
\hline \multicolumn{4}{|c|}{ Testudinidae } \\
\hline Manouria impressa & Terrestrial: forests on hills and mountains & & \\
\hline Indotestudo elongata & Terrestrial: evergreen and deciduous forest & yes & yes \\
\hline $\begin{array}{l}\text { Geochelone/Manouria } \\
\text { emys }\end{array}$ & Terrestrial: highland monsoon forest-dwelling & & \\
\hline
\end{tabular}

Notes:

1. Information about habitat preferences from Ernst and Barbour 1989.

2. Comparative collection property of Peter Pritchard.

species but-with one exception-were either terrestrial or preferred slowmoving waters with muddy bottoms.

A number of taxa are primarily found in terrestrial habitats. Indotestudo elongata can be found in both evergreen and deciduous forests. Several emydid species, including Heosemys grandis and Cuora amboinensis, are also common on land.

Cyclemys, Hieremys, and Morenia prefer slow-moving bodies of water, such as sluggish streams, swamps, and ponds. The presence of at least one of these species 
in the faunal sample suggests that this type of aquatic habitat was available in the vicinity of the rock shelter and was exploited by Pleistocene foragers.

Several other Southeast Asian taxa that prefer ponds and sluggish streams are missing from the Lang Rongrien sample. These are Notochelys, Siebenrockiella, and Malayemys. There is often a correlation between species identified in an archaeological assemblage and the species composition of the comparative collection, but representatives of these genera were available for comparison. Their absence in the sample cannot be explained at this time.

Dogania prefers clean hill streams. It is possible that the higher elevations in the vicinity of the rock shelter, although farther away from slow streams running through the valley bottoms, provided suitable habitat for this taxon of turtle.

No taxon currently found in highland environments or in mountain streams, such as Pyxidea, Heosemys spinosa, or Platysternon, were identified. It is unknown whether the relatively isolated Khao Ao Pong and Khao Phanom Bencha mountains support populations of these taxa even at the present time and whether their absence in the Lang Rongrien sample is unexpected. As skeletons of upland species were available for comparison, this pattern of species identification is not considered to be a reflection of limitations of the comparative turtle collection.

The environmental preferences of the turtle species found at Lang Rongrien Rockshelter indicate that sluggish or standing water was at least seasonally available in the Klong Yai and Krabi valleys. The lack of turtles requiring large, permanent bodies of water suggests that permanent ponds, swamps, or large rivers were not a feature of the environment. The presence of Indotestudo suggests that the vicinity of the cave was wooded.

\section{Birds}

Five elements were recognizably bird bones but could not be identified to species. A scapula fragment of an unidentified bird and the distal humerus of an unidentified duck were found in Unit 8. A single long bone of an unidentified small bird was found in Unit 9. Two long bone fragments were found in a hearth in Unit 10 .

\section{Mammals}

Some 1131 mammal bones weighing $2810 \mathrm{~g}$ were identified in the sample from Lang Rongrien. Mammal bones totaling 789 bones weighing $1376 \mathrm{~g}$ were identified in the sample from Unit 8; 94 bones weighing $438 \mathrm{~g}$ were found in Unit 9; 248 bones weighing $996 \mathrm{~g}$ came from Unit 10. Identified mammals were a small portion of the sample; only 25 bones were identified to the species or genus level. The small number of identified bones is due to a high fragmentation rate (the average mammal bone weighed $2.5 \mathrm{~g}$ ) and a dearth of skull elements (including teeth, which are usually preserved very well and are relatively easy to identify). The number of bones identifiable to family level, particularly Bovidae and Cervidae, was higher, but similarity in elements among many of the species precluded identifications to species or in some instances even to genus level (Bos versus Bubalus or small Cervus versus Axis, for example). 
Table 5. Habitat Preferences of Ungulate Species Identified at Lang Rongrien Rockshelter, Krabi Province, Thailand.

\begin{tabular}{|c|c|c|c|}
\hline SPECIES & HABITAT TYPE & FOOD PREFERENCE & $\begin{array}{l}\text { IDENTIFIED IN } \\
\text { UNITS 8-IO }\end{array}$ \\
\hline Cervus unicolor & Open forest, dense jungle & Browser-leaves and shrubs & Yes \\
\hline Cervus eldi & $\begin{array}{l}\text { Open forest, avoids dense } \\
\text { jungle }\end{array}$ & Grazer-grasses & Yes \\
\hline Elaphas maximus & Open forest/grasslands & Grazer-grasses & Yes \\
\hline Muntiacus muntjak & All types of forest & Browser-leaves and shrubs & Yes? \\
\hline Bos javanicus & Open forest/grasslands & Grazer-grasses & Yes? \\
\hline Axis porcinus & Grasslands & Grazer-grasses & No \\
\hline Bos gaurus & Open forest/grasslands & Both-leaves, shrubs, and grasses & No \\
\hline Bubalus arnee & Open forest/grasslands & Grazer-grasses & No \\
\hline Sus sp. & Open forest/dense jungle & Browser-leaves, fruits, flowers & No \\
\hline
\end{tabular}

\section{Deer}

The sambar (Cervus unicolor) is the largest deer in Southeast Asia, with females in Malaya recorded as weighing up to $162 \mathrm{~kg}$ and males weighing 185-200 kg (Medway 1969:109). Historically, sambar ranged from India to south China (Yunnan, Sichuan, and Guangdong Provinces) and south to Malaya, Sumatra, and Borneo (Corbet and Hill 1992:256). This species is found in a wide variety of habitats but prefers wooded areas, including dense jungle (Lekagul and McNeely 1977:687) (Table 5). It is highly mobile and moves from one habitat type to another between seasons. Srikosamatara (1993:37) notes that the density of sambar in dry tropical forest was twice as high in the wet season as in the dry season in a game reserve in western Thailand. Sambar are more browsers than grazers and generally feed on leaves and shrubs in areas of secondary growth.

Four bones were identified as being from a sambar. Two, a proximal left scapula and a proximal radius, were from Unit 8. A third element was a burned proximal ulna from Unit 9. The fourth was a metatarsal shaft fragment from Unit 10 that was tentatively identified as being from a sambar on the basis of size.

Eld's deer (Cervus eldi) stands about $120-130 \mathrm{~cm}$ at the shoulder and weighs 95-150 kg (Lekagul and McNeely 1977). It is currently limited to eastern India, Cambodia, and Laos (Corbet and Hill 1992:256). Formerly, however, it ranged from eastern India through Myanmar and Thailand to Vietnam and South China, and it occurred at least as far south as the Isthmus of Kra on the Malay Peninsula (Lekagul and McNeely 1977:688).

Eld's deer habitat consists of dry deciduous forests and open plains (Corbet and Hill 1992:256; Lekagul and McNeely 1977:688). A recent study of Eld's deer ecology indicates that relict populations of this endangered species co-occur with banteng in dipterocarp forest (McShea 2003) (see Table 5). This type of vegetation is characterized by high percentages of Shorea, Dipterocarpus, and Terminalia in open-canopy forests. Canopy coverage in open dipterocarp forest where Eld's deer were observed ranged from 15 to 45 percent. Eld's deer avoid dense forest and gallery forest that occur along the margins of streams and ponds. Gallery forests are leopard habitat, and leopards are know to hunt Eld's deer. 
A grazer rather than a browser, Eld's deer often feeds in rice fields and on grasses and forbs. Eld's deer also eat large quantities of fruit when available (McShea 2003).

Six bones from the Lang Rongrien sample have been identified as being from Eld's deer: a proximal metatarsal, an ilium fragment, two incisors, and a first phalanx from Unit 8. A mandibular fragment containing the third and fourth premolars and the first and second molars and a lower incisor were found in Unit 9. No Eld's deer elements were identified in the sample from Unit 10.

The muntjac, or barking deer (Muntiacus muntjak), weighs 20-28 kg, and stands 50-65 $\mathrm{cm}$ at the shoulder (Lekagul and McNeely 1977:675). This small species ranges throughout India, east to Tibet and Yunnan, and south to Malaya and islands on the Sunda Shelf (Corbet and Hill 1992:260). Muntjac occur in all types of forest and have been observed feeding on the edges of the forest and in abandoned clearings. The deer browse on leaves and shrubs and are fond of fallen fruits (Lekagul and McNeely 1977:677; Medway 1969:107). Only one element, a distal radius shaft from Unit 8 , was tentatively identified as being from a muntjac.

The hog deer (Axis porcinus) is named for the grunting sounds it makes. It weighs 70-110 kg (Lekagul and McNeely 1977:680). This species is widely distributed, ranging from Pakistan and north India to Myanmar, Thailand, Laos, and southern Vietnam (Corbet and Hill 1992:259). Hog deer are found mainly in habitats of tall grasses, such as grasslands and marshlands (Lekagul and McNeely $1977: 682)$. It feeds on grasses and is a grazer more than a browser. No hog deer elements were identified in the faunal samples from Units 8-10, but several were identified in Units 5 and 6 (see discussion below).

A number of bones were recognizable as deer but could not be identified to species. Four phalanges fragments and an incisor were found in Unit 8. A calcaneus fragment and an antler fragment were found in Unit 9. The antler fragment was burned and had been scored and snapped. A burned antler fragment was also recovered from Unit 10 .

\section{Cattle and Water Buffalo}

Four large wild bovid species are found in Southeast Asia: the banteng (Bos javanicus); the gaur (Bos gaurus); the water buffalo (Bubalus arnee); and the kouprey (Bos sauveli). Historic distribution of the kouprey suggests that this species was confined to the nonpeninsular Southeast Asian mainland. There are no palaeontological or historical records of the occurrence of this species on the Malay Peninsula.

The banteng, guar, and water buffalo have similar habitat preferences (see Table 5). Banteng prefer open habitat where edible grasses are available (Lekagul and McNeely 1977:705). Currently, the distribution of the wild banteng "lies in the zone of deciduous monsoon forest.... Habitats vary between the extremes of dry wooded parkland with large grassy plains to tropical rainforest with small clearings" (BOSTID 1983:43). They prefer to feed on grass but will also browse on shrubs, leaves, flowers, and fruits.

The wild gaur, a stockier animal than the banteng, generally inhabits similar environments, grazing in open forest and elephant grass jungles (Lekagul and 
McNeely 1977:702). Currently their distribution coincides with deciduous forests. They are opportunistic feeders and will graze or browse depending on available resources. Banteng and gaur have been observed together in a single herd (Medway 1969:110).

Water buffalo are also grazers but must have a shady place to lie during the heat of the day. This bovid prefers open forests and elephant grass jungles near swamps. They are true grazers and prefer grass to shrubs and leaves.

Five bones identified as bovid elements were recovered, two from Unit 8 and three from Unit 10. A burned distal fragment of a femur and a horn core fragment were found in Unit 8. A mandible fragment with a third molar, a proximal metacarpal fragment, and a first phalanx were found in Unit 10. The mandible fragment and the first phalanx appear to be most similar to the banteng in size and morphology.

\section{Wild Pigs}

Two species of wild pig are found on mainland Southeast Asia. One is the wild ancestor of the domestic pig, Sus scrofa, which bears the same Latin name. The other is the bearded pig, Sus barbatus. Sus scrofa is widely distributed from western Asia to southern China and down the Malay Peninsula (Corbet and Hill 1992 : 246). Lekagul and McNeely (1977:664) note that wild pigs are most common in wet forests and that during the dry season they are usually found along streambeds. The feral pig in the Hawaiian Islands weighs 60-90 kg (Diong $1973: 118)$.

Sus barbatus is currently confined to the Malay Peninsula and islands on the Sunda Shelf, excluding Java (Groves 1985). Bearded pigs in Malaya weigh between 75 and $200 \mathrm{~kg}$; females are smaller (Lekagul and McNeely 1977 :662).

Osteologically, it is difficult to discriminate between the two species, although differences in the lower canine teeth of adult males have been demonstrated (Groves 1981). Of the fauna from Units 8-10 at Lang Rongrien Rockshelter, only one element is tentatively identified as coming from a pig. This was a pelvic element, an ilium, from Unit 8.

\section{Elephants}

The historical distribution of the Asian elephant (Elephas maximus) includes the Malay Peninsula (Corbet and Hill 1992:239). It is found in a wide variety of forest types but avoids large areas of closed canopy forests. The Asian elephant feeds primarily on grasses and needs daily access to water. Skull elements identified as elephant by the excavators were encountered in Unit 8 and appear to consist primarily of tusk fragments. Although elephants are included on our list of identified taxa from Lang Rongrien Rockshelter, the fragments were not removed from the field and, although noted here, are not included in sample weights and counts.

\section{Wild Cats}

A large number of large and small cats are found in Southeast Asia (Corbet and Hill 1992). A medium-sized felid, either the Asian leopard (Panthera pardus) or 
the cloud leopard (Neofelis nebulosus), was identified in the sample from Lang Rongrien. Leopards occur from western Asia to southern China, throughout Southeast Asia, and down the Malay Peninsula (Corbet and Hill 1992:226). They are found in both low- and high-altitude forest (Medway 1969:97), preferring wooded country but also inhabiting open and shrubby environments (Lekagul and McNeely 1977:629). Rabinowitz and Walker (1991) observed that leopards were found in dry tropical forest mosaic habitat in western Thailand. They often frequent caves and rock shelters, especially pregnant females. The males may weigh up to $55 \mathrm{~kg}$; females are smaller (Medway 1969:97).

Three elements identified as being from a leopard were found in the Lang Rongrien sample. Two were distal metapodial fragments from Unit 8. A fragment of an ulna identified as being from a leopard was found in Unit 9. They were easily recognized as being from a felid and were most similar to Panthera pardus and Neofelis nebulosis in size. It is possible that these bones came from an animal that died naturally in the rock shelter. They were, however, found in association with other fragments that showed clear signs of cultural alteration, such as burning.

\section{Canids}

Besides the domestic dog (Canis familiaris), there are two species of wild dog in Southeast Asia. These are the golden Asiatic jackal (Canis aureus) and the dhole (Cuon alpinus). A single tooth - a maxillary third incisor from Unit 10-was tentatively identified as being from a canid, but on the basis of a single tooth, it is not possible to identify to species level. There were no other canid bones identified from Units 8,9 , or 10 .

\section{Unidentified Mammals}

The majority of mammal bones in all three units was unidentifiable to taxa but could be easily identified as to body part and designated as large, medium, or small-sized mammals. Only two small mammal bones were recovered. Assignment to size category is approximate, as small bone fragments from large species may resemble bones from medium-sized mammals, but it provides a way to characterize bones otherwise unidentified. Within each size category, the unidentified bones were further classified by body part: skull, limbs, vertebrae, or rib fragments. Bone weights and counts were used in this analysis as frequency indicators, as the sample was too small to employ more sophisticated measures. Even though unidentified to genus or species level, an examination of these categories of bones can often aid in understanding butchering or consumption practices. (Because the number of bones identified to taxa is so small, they are included in the counts of unidentified bones below to facilitate discussion of differences between proportions of body parts in the assemblage.)

Including the identified bones, a total of 50 large mammal bone fragments were found in Unit 8 (Table 6). Four limb fragments from large mammals were found in Unit 9, and 38 bone fragments were found in Unit 10. Large mammal bones consisted primarily of limb fragments; few vertebra, rib, or skull fragments were found. One of the large mammal skull parts was a horn core.

Bone fragments of medium-sized mammals were more common (Table 7). A 
Table 6. Counts and Weights of Large-Sized Mammal Bones in Faunal Sample from Units 8-io, Lang Rongrien Rockshelter, Krabi Province, Thailand (Includes Elements That Were Identified to Taxon; Weights in Grams).

\begin{tabular}{|c|c|c|c|c|c|c|c|c|c|c|}
\hline \multirow[b]{2}{*}{ UNIT } & \multicolumn{2}{|c|}{ LIMBS } & \multicolumn{2}{|c|}{ RIBS } & \multicolumn{2}{|c|}{ SKULL } & \multicolumn{2}{|c|}{ VERTEBRAE } & \multicolumn{2}{|c|}{ TOTALS } \\
\hline & No.* & wт. ${ }^{*}$ & No. & WT. & No. & WT. & No. & WT. & No. & WT. \\
\hline 8 & (4) 36 & (30) 412 & 5 & 15 & 2 & 5 & 7 & 18 & 50 & 450 \\
\hline 9 & (1) 3 & (17) 130 & - & - & (1) 1 & (21) 90 & - & - & 4 & 220 \\
\hline 10 & (1) 35 & (12) 523 & (1) 2 & (5) 7 & (2) 1 & (16) 47 & - & - & 38 & 577 \\
\hline Totals & 74 & 1065 & 7 & 22 & 4 & 142 & 7 & 18 & 92 & 1247 \\
\hline
\end{tabular}

* Counts and weights in parentheses refer to burned bones.

total of 735 bone fragments, including identified bones, were found in the sample from Unit 8 . The sample from Unit 9 included 90 bone fragments from mediumsize mammals. A total of 212 bone fragments from medium-sized mammals were found in the sample from Unit 10.

In comparison to large mammals, the sample of medium-sized mammal skeletal elements contained higher percentages of vertebra and rib fragments. As with large mammals, however, there were few skull elements identified in the sample. If the lack of recognizable skull parts were a function of fragmentation, one would expect to find a large number of well-preserved teeth in the sample. Teeth, however, were seldom encountered in the sample, suggesting that skull fragments were poorly represented in the Lang Rongrien faunal sample.

\section{Sample Size and Taxonomic Composition}

The Lang Rongrien faunal sample consists almost completely of terrestrial taxa, characterized by a high percentage of turtle and tortoise bones and a notable lack of pig. Grayson (1984) demonstrates that sample size affects species whose bones are present in small quantities more than species that dominate an assemblage.

Table 7. Counts and Weights of Medium-Sized Mammal Bones in Faunal Sample from Units 8-io, Lang Rongrien Rockshelter, Krabi Province, Thailand (Includes Elements That Were Identified to Taxon; Weights in Grams).

\begin{tabular}{|c|c|c|c|c|c|c|c|c|c|c|}
\hline \multirow[b]{2}{*}{ UNIT } & \multicolumn{2}{|c|}{ LIMBS } & \multicolumn{2}{|c|}{ RIBS } & \multicolumn{2}{|c|}{ SKULL } & \multicolumn{2}{|c|}{ VERTEBRAE } & \multicolumn{2}{|c|}{ TOTALS } \\
\hline & No.* & wT. * & NO. & WT. & NO. & WT. & NO. & WT. & NO. & WT. \\
\hline 8 & (89) 511 & (97) 643 & (55) 184 & (27) 156 & 7 & 32 & (6) 33 & (18) 91 & 735 & 922 \\
\hline 9 & (4) 60 & (1) 99 & (1) 9 & (2) 16 & 3 & 30 & (2) 18 & (8) 73 & 90 & 218 \\
\hline 10 & (38) 187 & (49) 342 & 13 & 19 & 9 & 20 & 3 & 37 & 212 & 418 \\
\hline Totals & 758 & 1084 & 206 & 191 & 19 & 82 & 54 & 201 & 1037 & 1558 \\
\hline
\end{tabular}

* Counts and weights in parentheses refer to burned bones. 
The Lang Rongrien assemblage is admittedly small and our sample is incomplete, but the presence of a larger sample is not likely to alter the present proportions of the major taxa. A larger sample from Lang Rongrien might affect the frequency of arboreal taxa such as primates, squirrels, and rodents that are small components of other Southeast Asian assemblages (see below). A larger sample might also increase the amount of identified pig, which is a common taxon in other Southeast Asian assemblages, but it is unlikely that a larger sample would elevate this species to a large proportion of the Lang Rongrien assemblage.

We argue here that a larger sample may increase the number of identified taxa that are normally represented in small numbers, but it will not alter the most salient features of the sample: a high percentage of turtles and tortoise and an absence of pigs. Turtle and tortoise bone is so pervasive that it is unlikely that a larger sample will minimize their relative contribution to the taxon composition. Pig bones are relatively stout for their size in comparison to deer, and it is improbable that many pig bones were present but failed to be identified in the Lang Rongrien assemblage.

Although the assemblage is small, there were few identified elements of large mammal axial skeletons, including skulls, vertebrae, or ribs (Table 8). Medium mammal vertebrae and rib elements were present in higher proportions than for large mammals, but the incidence of skull bones of both large and small mammals was low. Skull elements constituted 9 percent of the sample of large mammal bones by count and 14 percent by weight. Skull bones constituted less than 1 percent of the sample of medium mammal bones by count and 2 percent by weight.

This pattern of element distribution suggests that there was a greater tendency to leave large mammal axial elements, including the head, outside of the rock shelter, perhaps at a butchering station, while medium mammals were decapitated and transported whole to the shelter for further processing. Deer antlers appear to have been removed from the skull and curated as raw materials for tools, judging by the number of antler fragments in the sample, one of which had been altered.

\section{Origins of Lang Rongrien Faunal Assemblage}

The presence of bones in Lang Rongrien Rockshelter is likely to have come about in one of two ways: (1) Bones were transported to the rock shelter by humans or (2) bones were brought into the shelter by a nonhuman predator. Given the location of the rock shelter, high in the side of a karstic formation, it is unlikely that bones washed into the cave or that individual herbivores utilized the cave and died naturally.

Leopards are a good candidate for a nonhuman agent that transported bones into the cave. The presence of Asian leopard (Panthera pardus) or clouded leopard (Neofelis nebulosus) bones in the sample provides evidence that one or both species were in the region at the time of utilization of the rock shelter. These animalsparticularly pregnant females-den in caves, and it is possible that leopard kills contributed to the faunal assemblage at Lang Rongrien Rockshelter.

At present, there is little evidence to identify the bones that may have been introduced by leopards. One bone exhibits pitting typical of bones that have passed through a digestive tract, but no puncture marks were observed on other 
bones. Scavenging of human food refuse by leopards might account for the low numbers of skull parts. There were, however, several instances of relatively intact portions of turtle carapace and plastron.

Patterns of bone distribution, however, do suggest that meat processing and consumption took place at Lang Rongrien Rockshelter. In Unit 10, the oldest excavated unit, faunal remains were associated with four out of five of the hearths. The southernmost hearth did not contain any faunal remains (Anderson 1997) (Fig. 3). The bulk of the faunal sample analyzed from this unit came from

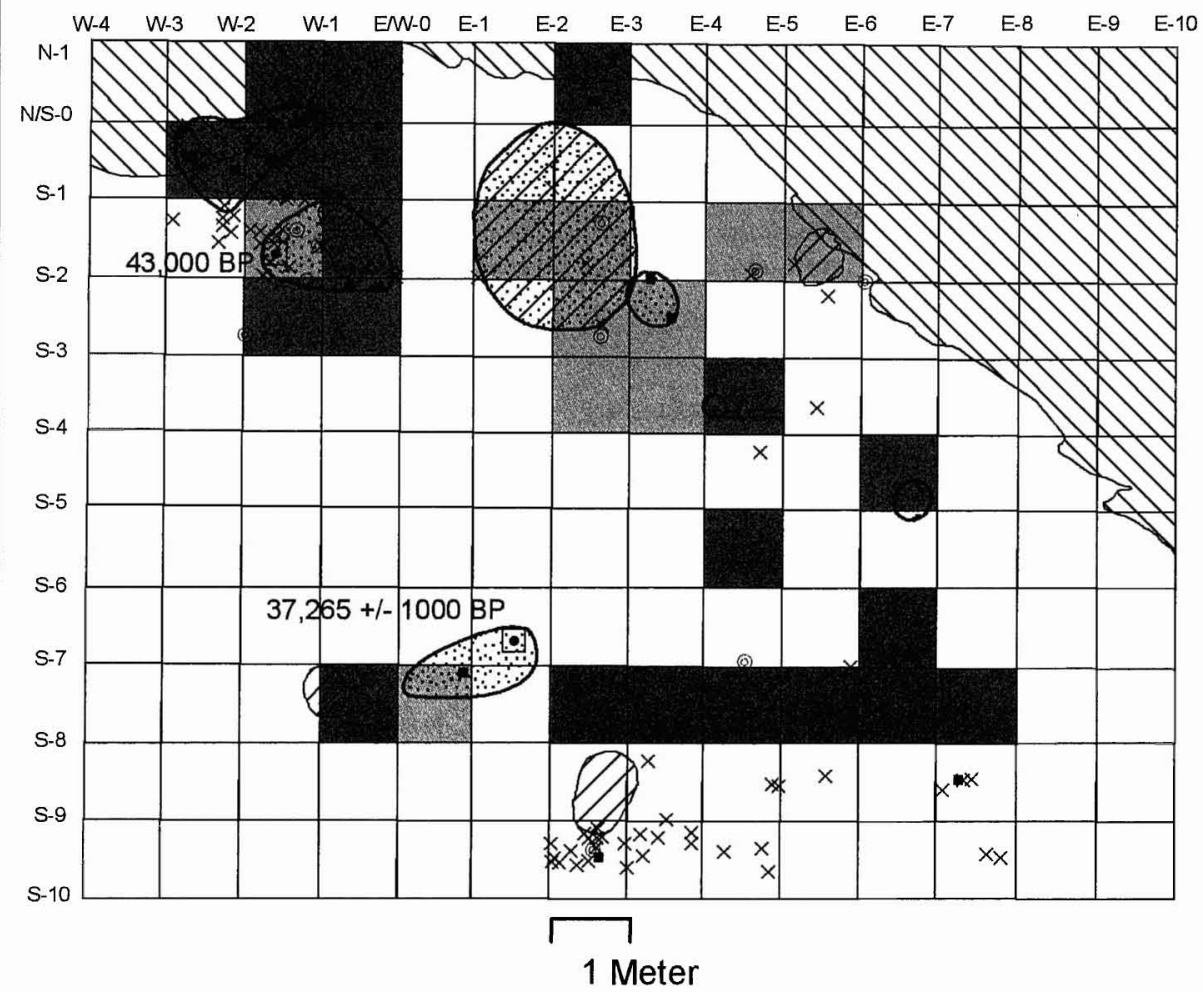

$\times$ Cultural object $\quad$ Charcoal and ash

- Bone Stone concentration

- Charcoal sample $B$ Bone concentration

- Dated C-14 sample $Z Z$ Hearth

Unit with analyzed bone Unit with unanalyzed bone Excavation Unit

$\$$ Cave wall 
a large hearth located at the back of the shelter. Four ash lenses were also identified: two associated with hearths and two in parts of the cave distant from hearths. Flakes and stone artifacts were clustered around the northwestern hearth in the rear of the cave and around the southernmost hearth in the front of the cave. In addition to bone fragments found around hearths, faunal remains were found in the southeastern part of the excavation in association with stone artifacts, suggesting that this was either an area for processing bones or that the bones and artifacts were discarded together.

Unit 9 contained eight hearth areas and four ash deposits in separate areas from the hearths (Anderson 1997) (Fig. 4). Faunal remains were concentrated in three areas at the back of the cave. One cluster was associated with a hearth. A second cluster was over the area of the large hearth in Unit 10 and was associated with a charcoal and ash deposit. The bulk of the faunal sample analyzed in this study came from this area. The third area was against the back wall of the cave and may represent disposal activities separate from processing. A number of hearths in Unit 9 had neither stone artifacts nor faunal remains.

Unit 8 contained remains of 12 separate hearths (Anderson 1997) (Fig. 5). Four hearths were associated with ash and charcoal deposits. Faunal remains were either clustered around hearths or deposited in a location in the rear of the cave that was situated above the ash deposit in Unit 9 and the large hearth in Unit 10.

This preliminary analysis suggests that faunal remains found in Units 8-10 were distributed in a nonrandom pattern at Lang Rongrien. The high densities of bones in the immediate vicinity of hearths or ash lenses suggest that bones were incorporated into these features as a result of processing and subsequent clearing of hearths. Mammal and turtle/tortoise bones co-occurred near hearths, suggesting that both types of meat were processed at the same time. The consistent high density of bones at the rear of the shelter may be a result of downward sloping of the ground surface in this area.

The bones exhibited signs of burning. Of the turtle and tortoise sample, 9 percent by weight and 17 percent by count were blackened. Both large and medium-sized mammal bones showed burn marks, 15 percent by count and 9 percent by weight.

At present, the evidence to support the hypothesis that a nonhuman agent introduced some or all of the faunal remains into the Lang Rongrien sample consists of several leopard bones and a bone that appears to have survived digestion by a carnivore. Evidence to support a hypothesis that humans introduced some or all of the faunal remains into the cave includes association of faunal remains with hearths and the large number of turtles, unlikely carnivore prey items, in the assemblage.

\section{DISCUSSION}

\section{Intersite Comparisons of Faunal Samples}

The unique characteristics of the Lang Rongrien sample can perhaps be best appreciated through comparison with fauna from upper levels of the same cave and with faunal assemblages from two other Pleistocene sites in Sundaland: Niah Cave and the Moh Khiew Rockshelter. Differences in assemblage composition may be related to one or more factors, including environmental variability in the 


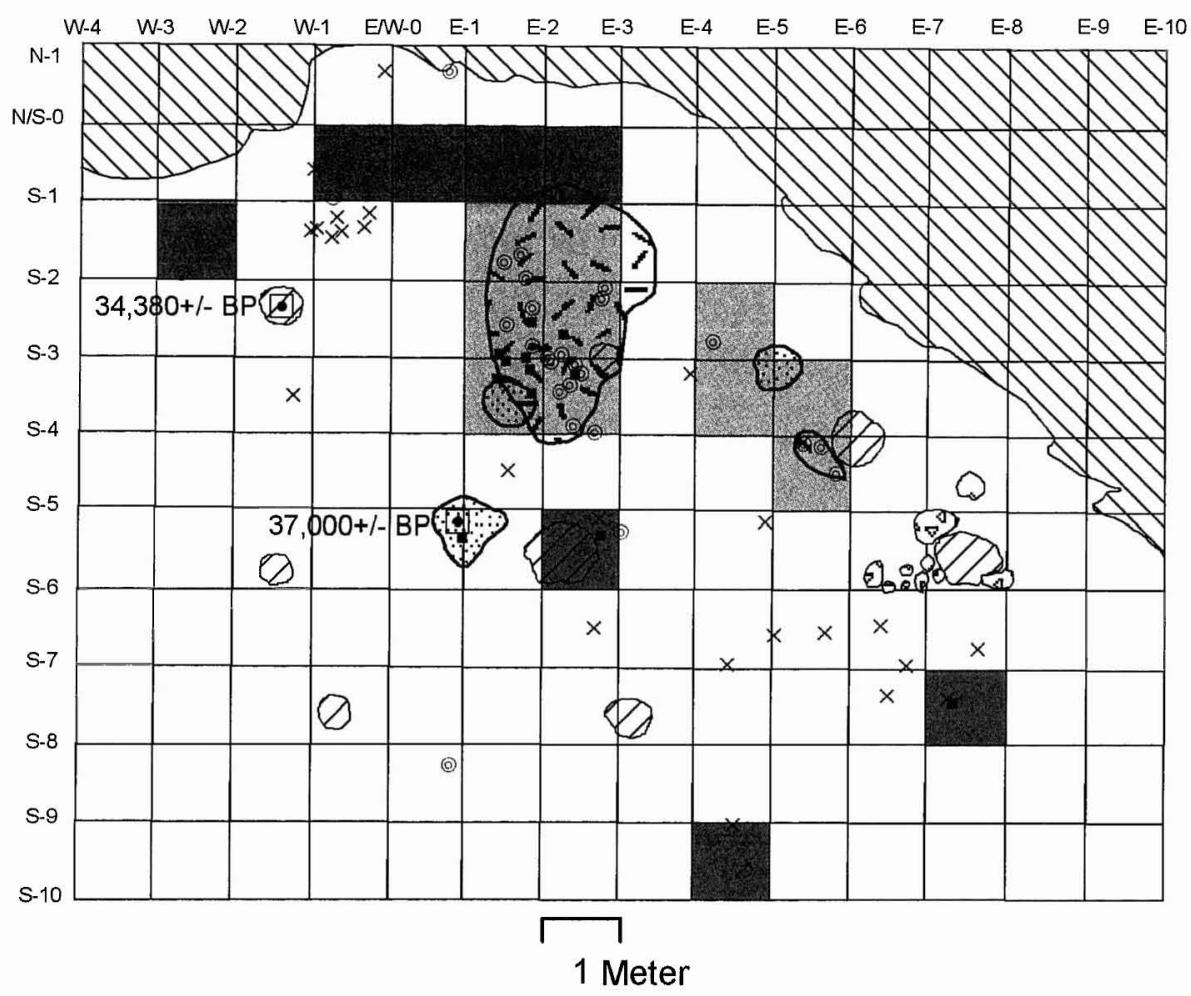

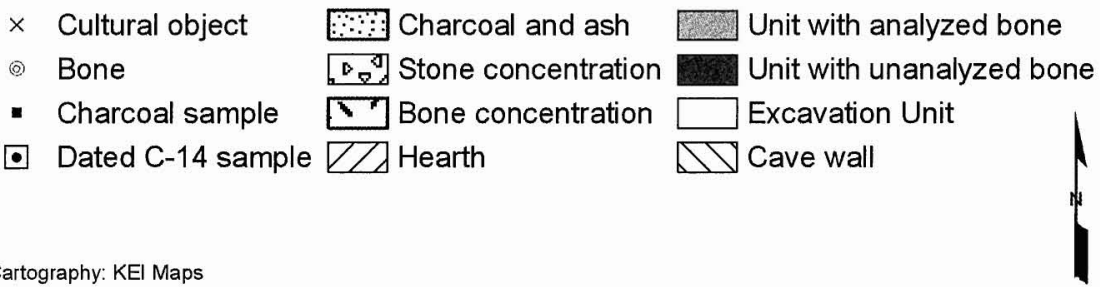

Fig. 4. Unit 9, Lang Rongrien Rockshelter.

catchment areas of the caves and differences in cave use. The comparison is structured by the available data from other analyses, consisting primarily of lists of identified taxa. It is unclear whether nonmammalian data were reported consistently. More detailed reporting of faunal assemblage composition might considerably change interpretations of Southeast Asian Pleistocene foraging strategies.

Niah Cave, Borneo - Niah Cave, now located only $16 \mathrm{~km}$ from the coast of western Sarawak (see Fig. 1), was located on the edge of the lowlands of eastern 


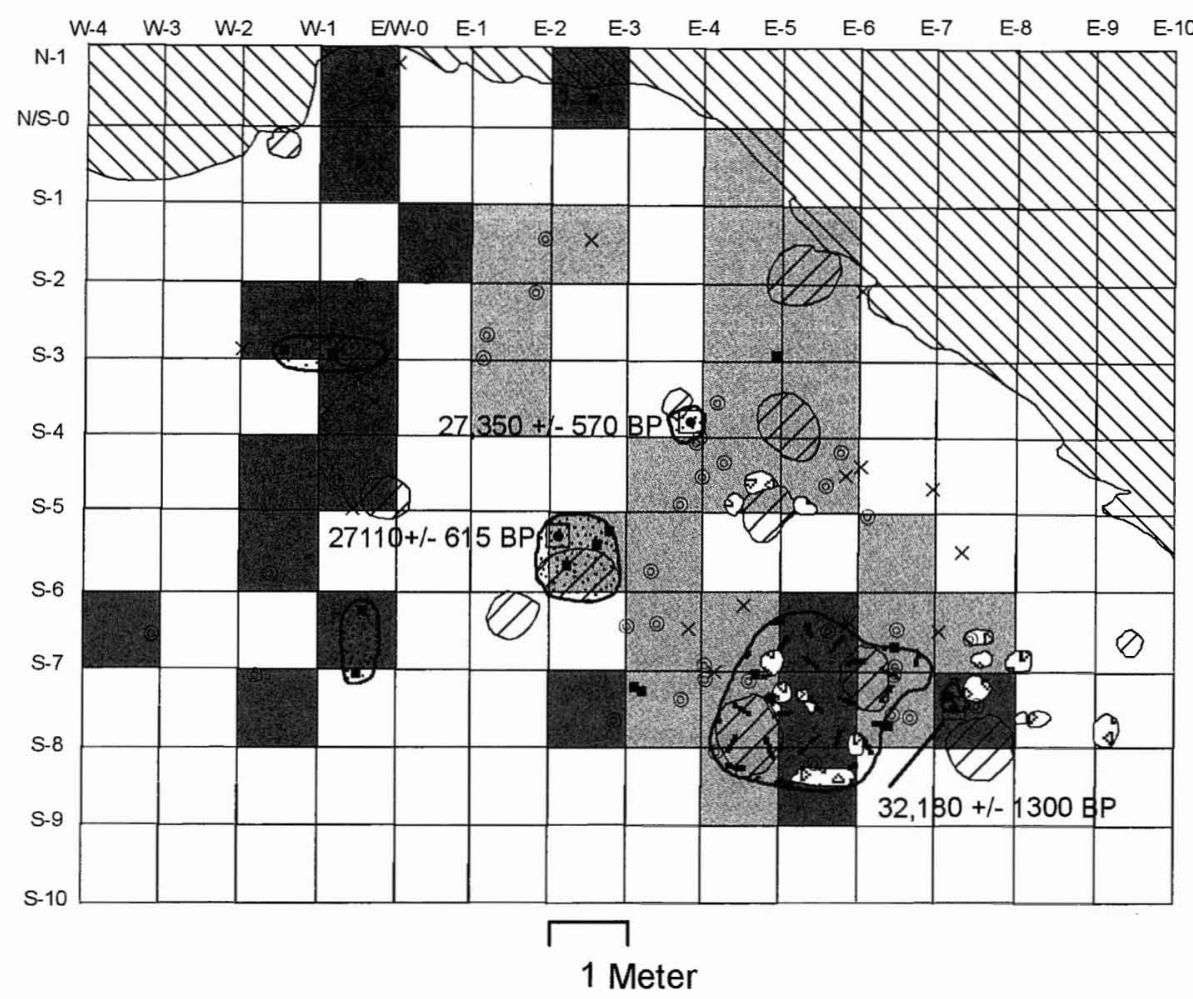
$\times$ Cultural object
Charcoal and ash
(2) Bone Drd Stone concentration Unit with analyzed bone
- Charcoal sample $D$ Bone concentration
- Dated C-14 sample $V 7 \lambda$ Hearth Unit with unanalyzed bone Excavation Unit NV Cave wall

Fig. 5. Unit 8, Lang Rongrien Rockshelter.

Sundaland during most of the Pleistocene, approximately $200 \mathrm{~km}$ inland from the eastern coast. Analysis of seabed cores from the South China Sea suggest that eastern Sundaland was covered by brackish lagoons and bays, fringed with widespread mangrove swamps and forests (Biswas, cited in Bellwood 1990:257) during this time period. The faunal assemblage from Niah Cave, however, is composed of taxa normally associated with forest rather than a mangrove environment, indicating exploitation of higher land to the southeast of the cave.

The Niah Cave excavations, spanning 40,000 years of occupation, are challeng- 
ing to comprehend. No detailed account of the original fieldwork or stratigraphic sections or plans of excavations of the site are available (Medway 1977a). A carbon sample taken approximately $183 \mathrm{~cm}$ below datum has been dated to $30,637 \pm 700$ B.c.; a sample taken at $254 \mathrm{~cm}$ below datum was dated to $39,543 \pm 1000$ B.C. (Zuraina 1982). Zuraina, who carried out additional excavations in the main entrance of the cave, designated cultural strata lower than 213 $\mathrm{cm}$ below datum as being a pre-Hoabinhian occupation, characterized by the presence of flake tools similar in production technology to the flake tools found at Lang Rongrien. Thus, the lower levels at Niah Cave approximately correspond to the Unit 8-10 occupations at Lang Rongrien Rockshelter.

Medway (1977a) lists the mammal species from the faunal assemblage at Niah Cave and the depths at which these species first appear in the assemblage. While it is possible to construct a taxa list for the earliest levels at Niah Cave from this information (Table 8), only presence or absence data for each species is available.

Based on depth below datum, 17 mammalian species (excluding bats) were identified from the early levels of Niah Cave. Arboreal species consist primarily of primates: leaf monkeys, macaques, and orangutans. Terrestrial species include pangolins, porcupines, rats, tapirs, pigs, mouse-deer, sambar, and large bovids.

It is not possible to quantify the relative contributions each species made to the faunal assemblage at Niah Cave with the information currently available. Medway, however, notes that "Bearded Pig (Sus scrofa) was consistently the most important mammalian quarry species." Bones and teeth of this pig occur abundantly at all levels (Medway 1997a:60). Harrison (1996) notes that pigs were "very common" in the assemblage, banteng were "quite common," and muntjac, sambar, and elephants were "rare."

Medway also mentions that "A notable change was the rather abrupt increase in the relative frequency of arboreal mammals (i.e. monkeys and tree squirrels) above the 48 inch (122 cm) level" (Medway 1997b:60). Technological developments may account for differences between Hoabinhian and pre-Hoabinhian faunal assemblages. Bellwood (1990) notes that Hoabinhian sites on the northern margins of the equatorial rain forests constitute settlement of an environment for which there is no record of previous habitation. He argues that technological developments, "perhaps the bow and arrow or, with less likelihood, the blowpipe," enabled Hoabinhian groups to subsist in equatorial rain forest environments (260). The low densities of terrestrial fauna in evergreen rain forest would have favored adaptive strategies that included exploitation of arboreal fauna, such as monkeys, squirrels, and birds. These species, which would have formerly been caught only in traps, would then have been accessible through direct predation.

A comparison of the species list from the early levels at Niah Cave with the Lang Rongrien sample reveals several notable differences: (1) Turtle and tortoise bones are not mentioned as significant components of the Niah Cave faunal assemblage, although they dominate the Lang Rongrien sample. Medway (1958:630) notes that freshwater turtles were present in Niah Cave, although in low numbers, but no species identifications were provided. (2) The arboreal mammal component of the Niah Cave fauna is absent from the Lang Rongrien sample. No arboreal mammal species were identified in the Lang Rongrien sample. (3) Bearded pig or wild pig, which is prevalent at Niah Cave, is largely absent at the Lang Rongrien shelter. 
Table 8. Identified Taxa from Niah Cave, Moh Khiew, and Lang Rongrien Rockshelter.

\begin{tabular}{|c|c|c|c|c|c|}
\hline IDENTIFIED TAXA & $\begin{array}{l}\text { NIAH CAVE }{ }^{1} \\
\quad \text { AFTER } \\
\text { I7,6I } 3 \text { B.P. }\end{array}$ & $\begin{array}{c}\text { LANG } \\
\text { RONGRIEN }^{2} \\
{\text { UNITS } S^{-6}}^{-6}\end{array}$ & $\begin{array}{c}\text { MOH } \\
\text { KHIEW }^{3}, \\
\text { LEVEL I I }^{2}\end{array}$ & $\begin{array}{l}\text { NIAH CAVE }{ }^{1} \\
\text { BEFORE } \\
\text { 30,673 B.P. }\end{array}$ & $\begin{array}{c}\text { LANG } \\
\text { RONGRIEN }^{2}, \\
\text { UNITS } 8-10\end{array}$ \\
\hline Moonrat Echinosorex gymnurus & $\mathrm{X}$ & & & & \\
\hline Lesser Gymnure Hylomys suillus & $\mathrm{X}$ & & & $\mathrm{X}$ & \\
\hline $\begin{array}{l}\text { White-toothed Shrew Crocidura of. } \\
\text { fuliginosa }\end{array}$ & $\mathrm{X}$ & & & $\mathrm{X}$ & \\
\hline (Lesser) Treeshrew Tupaia cf. minor & $\mathrm{x}$ & & & $\mathrm{x}$ & \\
\hline $\begin{array}{l}\text { Flying Lemur Cynocephalus } \\
\text { variegatus }\end{array}$ & $\mathrm{X}$ & & $\mathrm{X}$ & & \\
\hline Slow Loris Nycticebus coucang & $\mathrm{X}$ & & & & \\
\hline Leaf Monkeys Presbytis sp. & $\mathrm{X}$ & & $\mathrm{X}$ & $\mathrm{X}$ & \\
\hline Macaques Macaca $s p$ & $\mathrm{X}$ & & $\mathrm{X}$ & $\mathrm{X}$ & \\
\hline Gibbon Hylobates cf. muelleri & $\mathrm{X}$ & & & & \\
\hline Giant Pangolin Manis paleojavanica & $\mathrm{X}$ & & & $\mathrm{X}$ & \\
\hline Malay Pangolin Manis javanica & $\mathrm{X}$ & & & $\mathrm{X}$ & \\
\hline Giant Squirrel Ratufa affinis & $\mathrm{X}$ & & & & \\
\hline $\begin{array}{l}\text { Prevost's Squirrel Callosciurus } \\
\text { prevostii }\end{array}$ & $\mathrm{X}$ & & $\mathrm{X}$ & & \\
\hline Low's Squirrel Sunda sciurus lowii & $\mathrm{X}$ & & & $\mathrm{X}$ & \\
\hline $\begin{array}{l}\text { Tufted Ground Squirrel } \\
\text { Rheithrosciurus macrotis }\end{array}$ & $\mathrm{X}$ & & & & \\
\hline Mueller's Rat Rattus muelleri & $\mathrm{X}$ & & & $\mathrm{X}$ & \\
\hline $\begin{array}{l}\text { Long-tailed Giant Rat Rattus } \\
\text { sabanus }\end{array}$ & $\mathrm{X}$ & & & $\mathrm{X}$ & \\
\hline Bamboo Rat Rhizomys sp. & & & $\mathrm{X}$ & & \\
\hline Porcupine Hystrix or Thecurus sp. & $\mathrm{X}$ & & $\mathrm{X}$ & $\mathrm{X}$ & \\
\hline $\begin{array}{l}\text { Long-tailed Porcupine Trichys } \\
\text { lipura }\end{array}$ & $\mathrm{X}$ & & & & \\
\hline Canid Canis sp. or Cuon alpinus & $\mathrm{X}$ & $\mathrm{X}$ & & & $\mathrm{X}$ \\
\hline Sun Bear Helarctos malayanus & $\mathrm{X}$ & & & & \\
\hline Malay Weasel Mustela nudipes & $\mathrm{X}$ & & & & \\
\hline Ferret Badger Melogale orientalis & $\mathrm{X}$ & & & & \\
\hline Hairy-nosed Otter Lutra sumatrana & $\mathrm{X}$ & & & & \\
\hline $\begin{array}{l}\text { Oriental Small-clawed Otter } \\
\text { Aonyx cinera }\end{array}$ & $\mathrm{X}$ & & $\mathrm{X}$ & & \\
\hline Malay Civet Viverra tangalunga & $\mathrm{X}$ & & & & \\
\hline Bearcat Arctictis binturong & $\mathrm{X}$ & & & & \\
\hline $\begin{array}{l}\text { Banded Palm Civet Hemigalus } \\
\text { derbyanus }\end{array}$ & $\mathrm{X}$ & & & & \\
\hline Mongoose Herpestes sp. & $\mathrm{X}$ & & & & \\
\hline Tiger Panthera tigris & $\mathrm{X}$ & & & & \\
\hline Leopard Panthera pardus & & & & & ? \\
\hline Clouded Leopard Neofelis nebulosa & $\mathrm{X}$ & & & & ? \\
\hline Leopard Cat Felis bengalensis & & & & $\mathrm{X}$ & \\
\hline Malayan Tapir Tapirus indicus & & & & $\mathrm{X}$ & \\
\hline Elephant Elephas maximus & & & & & $\mathrm{X}$ \\
\hline Rhinoceros Dicerorhinus sp. & $\mathrm{X}$ & $\mathrm{X}$ & & & \\
\hline Pig Sus barbatus or $S$. scrofa & $\mathrm{X}$ & $\mathrm{X}$ & $\mathrm{X}$ & $\mathrm{X}$ & ? \\
\hline Large Mouse-deer Tragulus napu & $\mathrm{X}$ & & & $\mathrm{X}$ & \\
\hline $\begin{array}{l}\text { Small Mouse-deer Tragulus } \\
\text { javanicus }\end{array}$ & $\mathrm{X}$ & & & & \\
\hline Barking Deer Muntiacus muntjak & $\mathrm{X}$ & $\mathrm{X}$ & $\mathrm{X}$ & & ? \\
\hline
\end{tabular}


TABLE 8 (Continued)

\begin{tabular}{|c|c|c|c|c|c|}
\hline IDENTIFIED TAXA & $\begin{array}{c}\text { NIAH CAVE } \\
\text { AFTER } \\
\text { I7,6I3 B.P. }\end{array}$ & 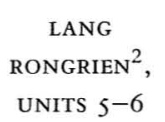 & $\begin{array}{c}\text { MOH } \\
\text { KHIEW }^{3} \text {, } \\
\text { LEVEL I }^{2}\end{array}$ & $\begin{array}{l}\text { NIAH CAVE } \\
\text { BEFORE } \\
\text { 30,673 B.P. }\end{array}$ & $\begin{array}{c}\text { LANG } \\
\text { RONGRIEN }^{2} \text {, } \\
\text { UNITS } 8-\text { IO }\end{array}$ \\
\hline Sambar Cervus unicolor & $\mathrm{X}$ & $\mathrm{X}$ & & $\mathrm{X}$ & $\mathrm{X}$ \\
\hline Bovid or Buffalo Bos or Bubalus & $\mathrm{X}$ & $\mathrm{X}$ & & $\mathrm{X}$ & $\mathrm{X}$ \\
\hline Hog Deer Axis porcinus & & $\mathrm{X}$ & & & \\
\hline $\begin{array}{l}\text { Hog Deer or Eld's Deer } A \text {. porcinus } \\
\text { or Cervus eldi }\end{array}$ & & ? & & & $\mathrm{X}$ \\
\hline Wild Fowl Gallus sp. & & $\mathrm{x}$ & & & \\
\hline
\end{tabular}

Notes: 1. Medway (1977b). 2. Kijngam in Anderson (1990). 3. Pookajorn (1996).

The lack of arboreal species of primates, rodents, and squirrels at Lang Rongrien, present in small numbers in the Niah Cave assemblage, may be a function of small assemblage size. We argue that the observed differences between Niah Cave and Lang Rongrien in terms of the absence of turtles and tortoises at the former and the absence of pigs at the latter is due to two factors: differences in the nature of environmental resources in the vicinity of the two sites and different lengths of stay at the two caves.

Although the environments may have been different in the vicinity of the cave and the rock shelter, we posit that the presence of arboreal mammal species in the faunal assemblage from Niah Cave stems from the use of the cave as a base camp that housed groups for relatively long periods of time. Extended residency at Niah Cave promoted exploitation of species that are present in rain forests in low densities or that are difficult to capture but cumulative over long periods of time in the archeological record of the cave.

In contrast, we argue, Lang Rongrien was used for short visits, during which time rare or difficult to capture species are unlikely to enter the faunal assemblage. Arboreal species may have been present in relatively high densities but, in general, are less frequently encountered than terrestrial species and are less likely to be captured. We argue that pigs were not present in the sample because they too were either absent or infrequently encountered in the local environment. We attempt to test this hypothesis by comparing the Lang Rongrien sample with a faunal assemblage from a cave in the same region.

Moh Khiew, Malay Peninsula - Excavations at the site of Moh Khiew, Trang Province, Thailand, allow us to compare faunal assemblages from a rock shelter in the same environmental zone as Lang Rongrien. Unlike Niah Cave, located $1700 \mathrm{~km}$ away in eastern Sundaland, Moh Khiew is about $13 \mathrm{~km}$ from Lang Rongrien, in the same karstic formation. The oldest cultural level at the rock shelter, Level 1, is dated to $25,800 \pm 600$ B.P. (Pookajorn 1996), approximately comparable to Unit 8 at Lang Rongrien. The lithic technologies and raw materials are comparable to the assemblage from Lang Rongrien, but the Moh Khiew assemblage is much larger: 102 tools, 721 "flake tools," and 367 waste flakes.

The list of species identifications for the faunal assemblage from Moh Khiew is available, but relative frequencies of each species' contribution were not pro- 
vided. Although the Lang Rongrien Unit 8 and Moh Khiew Level 1 samples are comparable in age and located in the same watershed, Moh Khiew is more similar to Niah Cave in species characteristics than to Lang Rongrien (see Table 8). Arboreal species of mammals, including leaf monkeys and Prevost's squirrel, are present, as are pigs. Turtles and tortoises are not mentioned as significant components of the Moh Khiew assemblage.

Location of the rock shelters in the same environment and utilized during the same general time period suggests that differences in faunal samples cannot be attributed to different animal resource availability. The relatively large size and variability in the lithic assemblage from Moh Khiew in comparison to the lithic assemblage from Lang Rongrien suggests that Moh Khiew was used for a base camp. Similarity between the Moh Khiew faunal assemblage and the Niah Cave assemblage may thus be a function of use of both caves as a base camp. Longterm stays and the subsequent accumulation of a large faunal assemblage would facilitate the inclusion of arboreal taxa that are difficult to capture. We suggest that differences between the Lang Rongrien and both the Moh Khiew and Niah Cave assemblages stem from use of Lang Rongrien for short stays during a seasonal round.

Lang Rongrien, Units 5 and 6-The Hoabinhian levels at Lang Rongrien, Units 5 and 6 , are dated to 8,300-10,000 B.P. By this time, Holocene climate conditions were established and were similar to conditions at present. Units 5 and 6 were composed of "numerous thin layers of obvious cultural origin" (Anderson $1990: 36)$. No traces of hearths or structures were encountered during the excavation. Lithic material, a single piece of pottery, and animal bones were recovered. The nature of cave utilization, whether as a short-term campsite or as a base camp, has not been determined.

A total of 273 identified bones come from Unit 5; 100 identified bones come from Unit 6 (Kijngam, cited in Anderson 1990). Only the numbers of bones identified to each taxa are reported; the size of the original assemblage is not given. Hog deer, wild fowl, rhinoceros, lizard, rat, small mammal, snake, and squirrel were identified. Pig bones constituted a significant proportion of the identified fauna in both units. A number of marine shells were also recovered from Units 5 and 6 . Although sea levels were higher, the coast was not appreciably closer: still $74 \mathrm{~km}$ distant (see Table 1). Estuarine resources that may now be under sediment layers produced by agricultural runoff, however, may have been closer to the cave. The assemblages from Moh Khiew and Units 5 and 6 of Lang Rongrien are more similar to each other than either is to Units 8-10 of Lang Rongrien in terms of number and kinds of identified species. Pigs are present, as well as arboreal species.

This limited comparison argues that environmental variations are insufficient to account for differences in the faunal samples from Moh Khiew and Niah Cave and those from Lang Rongrien. Similarities in environments during approximately the same time periods suggest that key differences in faunal assemblages from Lang Rongrien, Niah Cave, and Moh Khiew cannot be attributed to different animal resource availability. We suggest, however, that the length of time of habitation, whether short-term or long-term, and season of utilization, dry season or rainy season, may be key elements structuring differences in faunal assemblages 
from Lang Rongrien, Niah Cave, and Moh Khiew, rather than extraction technologies. The absence of pigs from the Lang Rongrien Unit 8-10 assemblage, however, deserves a closer consideration.

\section{Pigs and Habitat Reconstruction}

Pigs, both wild and domestic, are a key resource in the subsistence economy of traditional foraging and farming economies in Southeast Asia. "For hunters, wild pig is the desired prey.... For farmers, the domesticated hog is the mainstay of animal husbandry efforts, and the largest animal easy to breed and grow" (Griffin 1998:27). Like other foraging societies, hunter-gatherers in tropical environments require sources of dietary fat to metabolize and utilize vitamins and minerals. In Southeast Asia, these requirements are largely met by animals: pigs, pythons, and fish. Deer, while relatively common, do not store as much fat as pigs do. Pigs in good condition may have up to $5 \mathrm{~cm}$ of fat underlying their skin (Griffin 1998). In addition, pigs are complementary to fish, accumulating the thickest layers of fat in the wet season, when fish are generally thin-fleshed and difficult to obtain.

These brief observations suggest that if pigs were available in the catchment area of Lang Rongrien, they would have been hunted. Their absence from the faunal sample implies that they were not available. Why not?

It is possible that the people who utilized Lang Rongrien did so during a season of the year when pigs were undesirable or difficult to obtain. The Agta of northeastern Luzon, Philippines, employed two strategies for hunting pigs (Griffin 1998). During the wet season when pigs were fat, lone hunters or small parties, both without dogs, stalked pigs. During the dry season, larger parties with dogs hunted pigs. If people visited Lang Rongrien during the dry season, pigs may have been too difficult to capture, especially if domestic dogs were not available; or, if pigs were thin, it was not worth the trouble.

Another possibility is that pigs were present in the upper watershed of the palaeo-Krabi River, but they were in low densities and infrequently encountered by people making short-term visits to the rock shelter. Little research on wild Southeast Asian pig populations has been conducted, but studies on wild pig populations elsewhere indicate that, like many mammals, their reproductive biology is sensitive to changes in the availability of food, water, and shelter. These environmental parameters are inextricably linked to climate; changes in temperature and rainfall regimes affect fauna and flora on both a short-term and a longterm basis.

Studies of Pleistocene climate suggest that climatic conditions in Southeast Asia prior to the Last Glacial Maximum were drier and that rainfall was more seasonal than at present. A shift to a drier climate and seasonal availability of water may have had an effect on the density and encounter rate of pigs in the vicinity of Lang Rongrien. At present, there is little ecological data about Southeast Asian populations of wild pigs. Some information about wild pig populations' response to changing climatic conditions, however, is available from other regions of the world, where pigs pose a potential or real threat to crops and natural habitats.

During drought years, wild male pigs in southern Europe will lose up to 36 percent of their body weight and females up to 17 percent (Massei et al. 1996). 
This metabolic stress can result in lower birth weights and smaller litter size, and fewer adult females breed during years of reduced food availability. A study in Spain (Fernandez-Llario and Carranza 2000) documented a 70 percent decrease in the number of adult female pigs breeding during an extended drought. Multiple drought years can decrease the density of pigs on a long-term basis.

Pigs also have relatively high water requirements. Domestic pigs weighing 34$57 \mathrm{~kg}$ require 15-50 liters of water per day; pregnant and lactating sows require even more to produce adequate milk (Gillogly 1988:191). Variability in rainfall can cause a regional distribution of wild pigs to contract to areas near permanent water sources.

Forest density is another factor that may affect pig distribution. Pigs do not have sweat glands and rely on behavioral thermoregulation to maintain heat balance in hot environments (Baber and Coblenz 1986:519). They require dense cover and moist habitat and must have cool places to retreat to during the hottest parts of the day. The open-canopy forest, whose dominance is suggested by the presence of Eld's deer bones in the faunal sample, was probably not suitable habitat for pigs during the dry season, as they prefer closed-canopy forest.

Palaeoclimate and palaeobotanical data indicate that Sundaland was cooler prior to the Late Glacial Maximum, with lower and more seasonal precipitation than at present. Vegetation in many areas of Sundaland, including the vicinity of Lang Rongrien, was probably composed of mixed open-canopy forest and savannah. We argue that this was not suitable wild pig habitat, and that the distribution of pigs in Southeast Asia may have shrunk to well-watered areas of closed-canopy forests. The upper reaches of the watershed may have been more prone to intermittent water shortages than lowland areas, such as in the vicinity of Niah Cave. While turtles are present in the Lang Rongrien samples, the abilities of many species to estivate, a topic not explored here, buffer them from drought.

\section{CONCLUSIONS}

This study presents the results of an analysis of a faunal sample from a rock shelter in southern Thailand. The sample derives from three utilization episodes dating between 43,000 and 27,000 B.P. The sample was composed primarily of deer and bovids and freshwater and terrestrial turtles and tortoises. The presence of ungulate species that rely on grasses for forage and terrestrial turtle species that live in wooded areas suggests that the immediate environment of the rock shelter included both savannah-like habitat and open-canopy forest. A marine or estuarine fish bone was identified, implying direct exploitation of marine resources some distance away or contact with groups on the coast.

The faunal sample from Units 8-10 at Lang Rongrien Rockshelter is characterized by large proportions of turtle and tortoise bones, both shell fragments and limb bones, in all three units. The remaining portion of the Lang Rongrien sample consists primarily of unidentified large and medium-sized mammal bones, assumed to be largely from deer and bovids based on the elements identified to taxa.

Palaeobotanical research indicates that the closed-canopy forests of the Holocene were preceded by savannah or grasslands during and prior to the Last Glacial Maximum. The foraging preferences of the bovids, deer, and elephants (see Table 5) identified in the Lang Rongrien faunal sample suggest that both open forest 
and grassy areas occurred in the vicinity of the rock shelter. The presence of Eld's deer and the provisionally identified banteng suggests an open-canopy forest. The presence of grazers such as elephant suggests that some grasslands were present, but the absence of hog deer from the assemblage implies that grasslands were not the dominant habitat. Overall, the faunal sample indicates that a mosaic of environments was found in the vicinity of the rock shelter that included seasonal or permanent still water, such as ponds or slow areas of streams.

The Lang Rongrien faunal sample from Units 8-10 was compared to the identified fauna from Units 5 and 6 of Lang Rongrien, Niah Cave in Sarawak, and Moh Khiew Cave, Trang Province, Thailand.

The comparison emphasizes the unique attributes of the Lang Rongrien sample. The lack of pigs and abundance of tortoises and turtles contrasts markedly with species identifications in the other samples. Despite differences in the time period of occupation, geographical location, and perhaps technological innovations, the other three samples are all characterized by a wide diversity of species that includes arboreal mammalian and avian fauna and pigs.

The picture that is beginning to emerge from analysis of this sample is one of intermittent use of Lang Rongrien Rockshelter. The shelter is situated close to the boundary between coastal plain (now inundated) and interior flatlands, and the shelter may have been a locus in a seasonal round that involved transhumance from the subcontinental interior to the western marine coast.

The narrow range of species identified in the sample suggests that the shelter was used for short visits, rather than as a long-term base camp. The small size of the lithic assemblage and limited tool types that have been identified support this conclusion. The absence of arboreal species in the faunal assemblage is probably a function of a small assemblage size. Comparison with faunal assemblages from other Southeast Asian forager sites supports a conclusion that Lang Rongrien was occupied intermittently and, perhaps, seasonally.

This interpretation of utilization of the rock shelter has implications for developing accurate environmental reconstructions that are based on faunal assemblages. The absence of taxa from the Lang Rongrien faunal assemblage that are challenging to procure, such as arboreal primates and birds, is not an indication that these species are absent from the areas surrounding the rock shelter. The absence of these taxa is more likely to be a function of length of visit to the cave. Assemblages from base camps, which experience habitation events lasting months or years, are more likely to produce faunal assemblages that contain taxa representative of all species occurring in the environment.

Turtles and tortoises are a significant component of the Lang Rongrien sample, but the meat contribution of turtles and tortoises is relatively small in proportion to the number of elements identified. The ubiquity of turtle and tortoise bones in cultural features suggests, however, that turtles and tortoises were a constant element of the diet while at the cave and may have been a fairly reliable source of food, at least seasonally. Thus turtles and tortoises may have been a significant resource for maintaining levels of dietary protein in comparison to the erratic success of hunting mammals by active pursuit. Relatively easy to capture, especially if encountered on land, turtles and tortoises may represent the contribution of children and elderly people to the diet. 
We believe that a pattern of freshwater and terrestrial turtle utilization has not been previously recognized in Pleistocene Southeast Asian habitation sites, although it is well documented in other parts of the world (Stiner 1994). Lack of recognition of extensive turtle exploitation in Southeast Asian archeological sites may also be due to underreporting of the nonmammalian fauna by analysts who have focused primarily on the mammalian component of faunal assemblages.

Lang Rongrien is located in close proximity to a locally unique ecological area. Khao Phanom Bencha is over $1400 \mathrm{~m}$ in elevation; palynological research by Maloney and McCormac (1996) at sites of similar elevation in Sumatra suggests that high-altitude environments may have supported plant and animal communities that differed significantly from surrounding lowlands. Lang Rongrien Rockshelter may have provided habitation for foragers intending to harvest an as yet unidentified plant or animal resource.

Overall, these data suggest that Pleistocene foragers on the west side of Sundaland practiced a seasonal round that included both the marine coast, as indicated by marine or estuarine fish, and inland areas. The data also suggest that foraging strategies were more flexible and varied than previously documented for this time period in Southeast Asia, and included exploitation of tortoises and turtles, and perhaps high elevation resources. These foraging strategies were undoubtedly a contributing factor to colonization success in New Guinea and Australia.

\section{ACKNOWLEDGMENTS}

Analysis of the faunal sample was carried out while the senior author was a postdoctorate fellow in the Archaeobiology Program, Department of Anthropology, National Museum of Natural History, Smithsonian Institution, Washington, DC. Thanks goes to Mindy Zeder and Bruce Smith for their support of this project. Thanks also goes to Peter Pritchard for guidance in turtle identifications and for hosting the senior author while the work was carried out; and to Joyce White for assistance in locating references on climate and environmental reconstruction. Paula Molloy and Chris Tudge read early drafts of this paper and made many useful comments. Special thanks goes to three anonymous reviewers whose interest was demonstrated by careful reading and insightful comments. The senior author wishes to thank Dr. John Knoerl and T. Kurt Knoerl of KEI Maps for undertaking the cartography and hydrologic analysis used in this paper.

\section{REFERENCES}

AlLen, Jim

1996 Warreen Cave, in Report of the Southern Forests Archaeological Project: 135-165, ed. J. Allen. Bundoora: La Trobe University, Victoria, Australia.

Allen, Jim, and James F. O'connell

2003 The long and short of it: Archaeological approaches to determining when humans first colonized Australia and New Guinea. Australian Archaeology 57:5-19.

Anderson, Douglas D.

1990 Lang Rong Rien Rockshelter: A Pleistocene-Early Holocene Archaeological Site from Krabi, Southwestern Thailand. Philadelphia: University Museum, University of Pennsylvania.

1997 Cave archaeology in Southeast Asia. Geoarchaeology 12:607-638.

Baber, Daniel, and Bruce E. Coblenz

1986 Density, home range, habitat use, and reproduction in feral pigs on Santa Catalina Island. Journal of Mammalogy 67:512-525. 
BALME, J.

1980 An analysis of charred bone from Devil's Lair, Western Australia. Archaeology and Physical Anthropology in Oceania 15:81-85.

Bellwood, Peter

1990 From late Pleistocene to early Holocene in Sundaland, in Low Latitudes, vol. 2 of The World at 18,000 B.P.: 255-263, ed. C. Gamble. London: Unwin Hyman.

BOSTID

1983 Little Known Asian Animals with a Promising Economic Future. Advisory Committee on Technology Innovation, Board on Science and Technology for International Development (BOSTID), Office of International Affairs, National Research Council. Washington, DC: National Academy Press.

BOWDLER, SANDRA

1977 The coastal colonization of Australia, in Sunda and Sahul: 204-246, ed. J. Allen, J. Golsen, and R. Jones. London: Academic Press.

1996 The human colonization of Sunda and Sahul: Cultural and behavioral considerations. Bulletin of the Indo-Pacific Prehistory Association 14:37-42.

Burns, Stephen J., Dominik Fleitmann, Albert Matter, Jan Kramers, and Abdulkarim A. Al-Subbary

2003 Indian Ocean climate and absolute chronology over Dansgaard/Oeschger Events 9 to 13. Science 301 : 1365-1367.

Chappell, J., and N. J. Shackleton

1986 Oxygen isotopes and sea level. Nature 324:137-140.

Corbet, G. B., And J. E. Hill

1992 The Mammals of the Indomalayan Region: A Systematic Review. Oxford: Oxford University Press.

Dam, Rien A. C., Jennie Fluin, Papay Suparan, and Sander van der Kaars

2001 Palaeoenvironmental developments in the Lake Tondano area since 33,000 yr B.P. Palaeogeography, Palaeoclimatology, Palaeoecology 171:147-183.

DiONG, C. H.

1973 Studies of the Malayan wild pig in Perak and Johore. Malaysian Naturalist Journal 26:120151.

Dortch, C. E.

1979 Devil's Lair: An example of prolonged cave use in south-western Australia. World Archaeology 10:258-279.

ERnst, Carl H., and Roger W. Barbour

1989 Turtles of the World. Washington, DC: Smithsonian Institution Press.

Fernandez-Llario, P., and J. Carranza

2000 Reproductive performance of the wild boar in a Mediterranean ecosystem under drought conditions. Ethology, Ecology, and Evolution 12:335-343.

FOX, ROBERT

1970 The Tabon Caves. National Museum Monographs. Manila: National Museum of the Philippines.

GILlOGLY, Katherine

1988 The Ethnography of Animal Husbandry in Lowland Thailand: Aspects of Human, Animal, and Crop Interaction. M.A. thesis. University of Hawai'i, Honolulu.

GLOver, IAN

1981 Leang Burung 2: An Upper Paleolithic rock shelter in south Sulawesi, Indonesia. Modern Quaternary Research in Southeast Asia 6:1-38.

Grayson, Donald K.

1984 Quantitative Zooarchaeology. New York: Academic Press.

Griffin, P. Bion

1998 An ethnographic view of the pig in selected traditional Southeast Asian societies, in Ancestors for the Pigs: Pigs in Prehistory: 27-37. MASCA Research Papers in Science and Archaeology. Philadelphia: University of Pennsylvania Museum of Archaeology and Anthropology. 
Groube, L., J. Chappell, J. Muke, and D. Price

1986 A 40,000 year old human occupation site at Huon Peninsula, Papua New Guinea. Nature $324: 453-455$.

Groves, Colin

1981 Ancestors for the Pigs: Taxonomy and Phylogeny of the Genus Sus. Technical Bulletin Number 3. Canberra: Department of Prehistory, Research School of Pacific Studies.

1985 On the agriotypes of domestic cattle and pigs in the Indo-Pacific Region, in Recent Advances in Indo-Pacific Prehistory: 429-437, ed. V. N. Misra. New Delhi: Oxford and IBH Publishing Co.

HARRISON, TERry

1996 The paleoecological context at Niah Cave, Sarawak: Evidence from the primate fauna. Indo-Pacific Prehistory Association Bulletin 14:90-100.

Harrisson, TOM

1970 The prehistory of Borneo. Asian Perspectives 13:17-46.

Holdaway, Simon, and Nick Porch

1996 Dates as data, in Site Descriptions, Stratigraphies and Chronologies, ed. Jim Allen. Vol. 1 of Report of the Southern Forests Archaeological Project: 251-275. Bundoora: La Trobe University, Victoria, Australia.

Hope, GeOFFrey

2001 Environmental change in the late Pleistocene and later Holocene at Wanda site, Soroako, south Sulawesi, Indonesia. Palaeogeography, Palaeoclimatology, Palaeoecology 171:129145 .

KEALHOFER, LISA

2002 Changing perceptions of risk: The development of agro-ecosystems in Southeast Asia. American Anthropologist 104 : 178-194.

2003 Looking into the gaps: Land use and the tropical forests of southern Thailand. Asian Perspectives $42: 72-95$.

Lambeck, Kurt, and John Chappell

2001 Sea level change through the last glacial cycle. Science 292:679-686.

Lekagul, Boonsong, and John A. McNeely

1977 Mammals of Thailand. Bangkok: Association of Wildlife Conservation Publications.

Maloney, B. K., And F. G. McCormac

1996 Palaeoenvironments of north Sumatra: A 30,000 year old pollen record from Pea Bullock. Bulletin of the Indo-Pacific Prehistory Association 14:73-82.

Massei, Giovanna, Peter V. Genov, and Brian W. Staines

1996 Diet, food availability, and reproduction of wild boar in a Mediterranean coastal area. Acta Theriologica $41: 307-320$.

MCShea, WILliam

2003 Southeast Asia's deer: A legacy of war and oppression. Public lecture at the National Zoological Park, Smithsonian Institution, Washington, DC, March 6.

Medway, Lord

1969 The Wild Animals of Malaya. Kuala Lumpur: Oxford University Press.

1977a The wild pig remains from the west mouth, Niah Cave. Sarawak Museum Journal 25:2133.

$1977 \mathrm{~b}$ The Niah excavations: An assessment of the impact of early man on mammals in Borneo. Asian Perspectives $21: 51-69$.

Mulvaney, John, and Johan Kamminga

1999 Prehistory of Australia. Washington, DC: Smithsonian Institution Press.

Ollier, C. D.

1980 The geological setting, in Indonesia: The Making of a Culture: 5-20, ed. J. J. Fox. Canberra: Research School of Pacific Studies, Australian National University.

Pearce, R. H., and M. Barbetti

1981 A 38,000 year old archaeological site at Upper Swan, Western Australia. Archaeology and Physical Anthropology in Oceania 16:173-178. 
PENNY, DAN

2001 A 40,000 year palynological record from north-east Thailand: Implications for biogeography and palaeo-environmental reconstruction. Palaeogeography, Palaeoclimatology, Palaeoecology $171: 97-128$.

POOKAJORN, SURIN

1996 Human activities and environmental changes during the late Pleistocene to middle Holocene in southern Thailand and Southeast Asia, in Humans at the End of the Ice Age: 201213, ed. Lawrence Guy Straus, Berit Valentin Eriksen, Jon M. Erlandson, and David R. Yesner. New York: Plenum Press.

Rabinowitz, Alan R., and Susan R. Walker

1991 The carnivore community in a dry tropical forest mosaic in Huai Kha Khaeng Wildlife Sanctuary, Thailand. Journal of Tropical Ecology 7:37-47.

Rindos, D., AND E. WeBB

1992 Modeling the initial human colonization of Australia: Perfect adaptation, cultural variability, and cultural change. Proceedings of the Australasian Society for Human Biology $5: 441-454$.

Srikosamatara, SompoAd

1993 Density and biomass of large herbivores and other mammals in a dry tropical forest, western Thailand. Journal of Tropical Ecology 9:33-43.

STINER, MARY

1994 Honor among Thieves. A Zoological Study of Neandertal Ecology. Princeton, NJ: Princeton University Press.

Tijia, H. D., F. Shoji, And K. Kunihiko

1977 Changes of sea level in the Southern China Sea area during Quarternary times, in Quaternary Geology of the Malay-Indonesian Coastal and Offshore Areas: Proceedings of the Symposium, Held on 29 November 1976, at Kuala Lumpur, Malaysia in Conjunction with the Thirteenth Session of CCOP. Bangkok: UN ESCAP CCOP Technical Publication.

WALKER, D.

1980 The biogeographic setting, in Indonesia: The Making of a Culture: 21-34, ed. J. J. Fox. Canberra: Research School of Pacific Studies, Australian National University.

White, Joyce C., Daniel Penny, Lisa Kealhofer, and Bernard Maloney

2003 Vegetation changes from the late Pleistocene through the Holocene from three areas of archaeological significance in Thailand. Quaternary International 113:111-132.

ZuRAINA, MAJID

1982 The West Mouth, Niah, in the prehistory of Southeast Asia. Sarawak Museum Journal $31: 1-200$.

\begin{abstract}
This study reports on analysis of a sample of animal bones from Pleistocene levels of Lang Rongrien Rockshelter, Thailand. Analysis identified small proportions of marine and/or freshwater fish bone, freshwater/terrestrial snail shells, and bird bones, as well as large proportions of tortoise, turtle, and mammal bones. Comparison with three other faunal assemblages underscores salient characteristics consisting of a high proportion of turtle and tortoise and an absence of pigs in the Lang Rongrien sample. Analysis of the faunal assemblage suggests that, in contrast to other sites such as Niah Cave and Moh Khiew that were occupied on a long-term basis, the Pleistocene levels of Lang Rongrien were intermittently occupied by foragers who may have been practicing a seasonal round that involved transhumance from interior to coast. Keywords: Pleistocene, faunal analysis, climate reconstruction, pigs, subsistence, Thailand, Southeast Asia.
\end{abstract}


APPENDIX. HYDROLOGIC GIS ANALYSIS FOR PREPARATION OF FIGURE 2: RECONSTRUCTION OF RIVERINE PALEO-CHANNELS AND PLEISTOCENE SHORELINES IN THE VICINITY OF LANG RONGRIEN ROCKSHELTER.

Increasingly, Geographic Information Systems (GIS) is being used to visualize archaeological, hydrological, and other important concepts which, in turn, serve to increase scientific communication among archaeologists. The objective of this analysis was to generate a stream network model for the submerged coastal shelf west of Lang Rongrien Rockshelter, Krabi Providence, Thailand. Included in the study area was the submerged bottom of Phangna Bay. The resulting stream network approximates the drainage that was present at the times that the site was utilized. The stream network model was generated using ArcView GIS 9.0, GIS software by ESRI'® Spatial Analyst extension, and data from the Similan Islands to Ko Libong Map (2nd Edition), U.S. Naval Oceanographic Office, 1963 (Item 3760). Generating the stream network requires a seven-step model.

Step 1: Digitizing sounding points. Using the above referenced map, 3,260 sounding points were digitized. Additionally, each point's depth (in meters) was entered in the attribute table associated with the sounding points.

Step 2: Generating a bathymetric surface. The bathymetric surface was created using Spatial Analyst's "Interpolate to Raster" tool, following an Inverse Distance algorithm with a search radius of the twelve nearest sounding points from the target sounding point.

Step 3: Determining the direction of water flow over the bathymetric surface. This map layer was created by Spatial Analyst's "Flow Direction" tool. The tool looks at each pixel on the bathymetric surface and compares its depth to that of its surrounding nearest neighbors. It then identified which neighboring pixel had the lowest depth and records the direction (north, northeast, east, etc.) from the target pixel to that neighboring pixel with the lowest value. A new map layer called flow_direction is created as a result. This map layer played a key role in identifying sinks (see step 4 below) and creating the stream network (see step 5 below).

Step 4: Creating a sink-less bathymetric surface. Due to the spacing of data points, errors can be introduced into the creation of a surface. These errors must be identified and eliminated before proceeding any further in the hydrologic analysis. When an area is circumscribed by higher elevation values a sink is formed. In consequence, when modeling the flow of surface water the water drains into the artificial sink and goes no further. This distorts and hampers construction of a stream network since discontinuities are introduced. Spatial Analyst identifies sinks through the "sink" tool, which systematically passes over the bathymetric surface and tags pixels on the map that are sinks. Once tagged, the sinks can be filled using the Spatial Analyst's "Fill" tool. A total of 154 sinks were identified and filled in this bathymetric surface map layer.

Step 5: Generating a flow accumulation map layer. This map layer is formed by identifying all of the pixels of higher elevation around each pixel on the bathymetric surface. The number of up-slope pixels is recorded for each pixel. This is accomplished by using Spatial Analyst's "Flow Accumulation" tool. Once the count for all pixels is completed, a threshold value eliminate pixels whose counts are too low to be part of the stream network. All pixels that are below the 
threshold are assigned "No Data" value. The residual pixels present a linear stream network. A value of 100 was used as the threshold for this analysis.

Step 6: Converting the pixel or raster map layer to a vector or ESRI® Shapefile. The resulting shapefile contains polylines representing the stream network.

Step 7: Editing the stream network shapefile. Visual comparison of the original sounding points with the resulting map identified inconsistencies in the flow direction of stream segments. For the most part, inconsistencies were limited to the upper reaches of the stream network. These were edited to extend them to the mouths of the current streams that are on the modern landmass. 